ARTICLE

\title{
A potent and protective human neutralizing antibody targeting a novel vulnerable site of Epstein-Barr virus
}

\author{
Qian-Ying Zhu',2,9, Sisi Shan (10) ${ }^{3,9}$, Jinfang Yu (i] ${ }^{4,9}$, Si-Ying Peng ${ }^{5}$, Cong Sun (1) ${ }^{1}$, Yanan Zuo ${ }^{3}$, Lan-Yi Zhong ${ }^{1}$, \\ Shu-Mei Yan ${ }^{1}$, Xiao Zhang ${ }^{1}$, Ziqing Yang ${ }^{3}$, Yong-Jian Peng ${ }^{1}$, Xuanling Shi ${ }^{3}$, Su-Mei Cao ${ }^{6}$, Xinquan Wang (1) ${ }^{4 凶}$, \\ Mu-Sheng Zeng (i] ${ }^{1 凶} \&$ Linqi Zhang (1) ${ }^{3,7,8 凶}$
}

Epstein-Barr virus (EBV) is associated with a range of epithelial and B cell malignancies as well as autoimmune disorders, for which there are still no specific treatments or effective vaccines. Here, we isolate EBV $\mathrm{gH} / \mathrm{gL}$-specific antibodies from an EBV-infected individual. One antibody, 1D8, efficiently neutralizes EBV infection of two major target cell types, B cells and epithelial cells. In humanized mice, 1D8 provides protection against a high-dose EBV challenge by substantially reducing viral loads and associated tumor burden. Crystal structure analysis reveals that $1 \mathrm{D} 8$ binds to a key vulnerable interface between the D-I/D-II domains of the viral $\mathrm{gH} / \mathrm{gL}$ protein, especially the $\mathrm{D}-\mathrm{Il}$ of the $\mathrm{gH}$, thereby interfering with the $\mathrm{gH} / \mathrm{gL}$ mediated membrane fusion and binding to target cells. Overall, we identify a potent and protective neutralizing antibody capable of reducing the EBV load. The novel vulnerable site represents an attractive target that is potentially important for antibody and vaccine intervention against EBV infection.

\footnotetext{
${ }^{1}$ State Key Laboratory of Oncology in South China, Collaborative Innovation Center for Cancer Medicine, Guangdong Key Laboratory of Nasopharyngeal Carcinoma Diagnosis and Therapy, Sun Yat-sen University Cancer Center (SYSUCC), 510060 Guangzhou, China. ${ }^{2}$ Department of Laboratory Medicine, The Eighth Affiliated Hospital, Sun Yat-sen University, Shenzhen 518003, PR China. ${ }^{3}$ NexVac Research Center, Comprehensive AIDS Research Center, Center for Infectious Diseases Research, Beijing Advanced Innovation Center for Structural Biology, School of Medicine, Tsinghua University, 100084 Beijing, China. ${ }^{4}$ The Ministry of Education Key Laboratory of Protein Science, Beijing Advanced Innovation Center for Structural Biology, Beijing Frontier Research Center for Biological Structure, Collaborative Innovation Center for Biotherapy, School of Life Sciences, Tsinghua University, 100084 Beijing, China. ${ }^{5}$ Bejing IDMO Company Limited, Beijing, China. ${ }^{6}$ State Key Laboratory of Oncology in South China, Department of Cancer Prevention Research, Sun Yat-sen University Cancer Center (SYSUCC), 510060 Guangzhou, China. ${ }^{7}$ Institute of Biopharmaceutical and Health Engineering, Tsinghua Shenzhen International Graduate School, Tsinghua University, 518055 Shenzhen, China. ${ }^{8}$ Institute of Biomedical Health Technology and Engineering, Shenzhen Bay Laboratory, 518132 Shenzhen, China. ${ }^{9}$ These authors contributed equally: Qian-Ying Zhu, Sisi Shan, Jinfang Yu. ${ }^{{ }}$email: xinquanwang@mail.tsinghua.edu.cn; zengmsh@sysucc.org.cn; zhanglinqi@mail.tsinghua.edu.cn
} 
pstein-Barr virus (EBV) is associated with a wide range of diseases in humans such as infectious mononucleosis and lymphoproliferative disorders, as well as epithelial and B cell malignancies including nasopharyngeal carcinoma and Burkitt's lymphoma ${ }^{1-5}$. Despite decades of research, a safe and effective vaccine against EBV still remains elusive, largely due to a lack of knowledge regarding the specificity and magnitude of immune responses required for protection ${ }^{6-10}$. EBV-infected individuals produce broad and potent neutralizing antibodies that can inhibit infection of both epithelial cells and B cells in vitro ${ }^{11-15}$. However, their specificity to viral antigens and potential mechanism of neutralization are not clear.

Recent studies on monoclonal antibodies (mAbs) revealed some of the intricate interactions between antibodies and viral surface antigens, providing critical insights into the potential targets for antibody neutralization and vaccine development ${ }^{16-20}$. The reported mAbs recognize exclusively viral surface glycoproteins that work in concert in determining viral tropism and mediating viral fusion with the target cells, such as gp350, gH/gL, $\mathrm{gB}$, and gp42 $21-24$. Recently, $\mathrm{gH} / \mathrm{gL}$ and $\mathrm{gB}$, which together constitute the fusion machinery of EBV, have drawn increasing attention as newer generations of antibodies targeting this machinery demonstrate broad and potent inhibitory activity against EBV infection of both B cells and epithelial cells ${ }^{25,26}$, as well as cross-neutralizing reactivity to related herpesviruses of non-human primate $11,27,28$

As components of the fusion machinery, $\mathrm{gH} / \mathrm{gL}$ and $\mathrm{gB}$ demonstrate unique structural and functional features that are critical for viral entry, but they also inadvertently expose some vulnerable sites during the process, and become susceptible to antibody binding and neutralization ${ }^{29-31}$. The $\mathrm{gH} / \mathrm{gL}$ protein consists of four distinct domains named domain-I (D-I) to domain-IV (D-IV), forming an elongated structure ${ }^{32}$. D-I is formed by $\mathrm{gL}$ and the $\mathrm{N}$-terminus of $\mathrm{gH}$, while $\mathrm{D}$-II to D-IV are formed by the rest of $\mathrm{gH}$. D-I and D-II are connected through a linker helix and form a structurally distinct groove. For viral fusion to occur, $\mathrm{gH} / \mathrm{gL}$ must interact with $\mathrm{gB}$, which triggers a cascade of events involving dramatic structural changes of $\mathrm{gB}$ from the pre- to the post-fusion conformation ${ }^{30,31}$. Mutations in the D-I and D-I/D-II interfaces of $\mathrm{gH} / \mathrm{gL}$ were shown to affect the membrane fusion process, suggesting that these regions of $\mathrm{gH} / \mathrm{gL}$ are important for the interaction and activation of $\mathrm{gB}^{33,34}$.

Apart from the fusion machinery, EBV infection requires additional surface glycoproteins to complete the entry process, but the accessory molecules involved are rather different between $B$ cells and epithelial cells ${ }^{35}$. For instance, EBV utilizes gp350, one of the most abundant glycoproteins on the viral envelope, to attach to the cell surface through high-affinity interaction with CD21 or CD35 in B cells infection ${ }^{36-38}$. Such attachment promotes the bridging effect of another surface glycoprotein, gp42, which inserts itself between $\mathrm{gH} / \mathrm{gL}$ and human leukocyte antigen (HLA) class II, to trigger the downstream fusion machinery 39,40 . Interestingly, gp42 has an inhibitory effect on epithelial cell infection, suggesting a different entry mechanism in B cells and epithelial cells ${ }^{41}$. For infection of epithelial cells, gH/gL first binds to integrin and NMHC-IIA ${ }^{42}$ on the cell surface. The fusion machinery then interacts with neuropilin 1 (NRP1) and ephrin receptor A2 (EphA2) ${ }^{43-45}$, which leads to a conformational transition of $\mathrm{gB}$, facilitating viral fusion ${ }^{30,46}$.

Most of the current anti-gH/gL antibodies are of murine origin $^{39,47}$. E1D1, CL59, and CL40 can block epithelial cell infection but fail to efficiently neutralize B cell infection ${ }^{24}$. A human neutralizing antibody targeting $\mathrm{gH} / \mathrm{gL}$, AMMO1, was recently isolated from an EBV-infected individual ${ }^{24}$. AMMO1 can potently block infection of both $B$ cells and epithelial cells in vitro. AMMO1 can also protect humanized mice from EBV challenge and provide sterilizing immunity in macaques against oral challenge with rhesus lymphocryptovirus, the EBV homologue that infects rhesus macaques ${ }^{28}$. These findings indicate that a vaccine capable of inducing AMMO1-like neutralizing antibodies may protect human from EBV infection. Cryo-electron microscopy (cryoEM) analysis of the AMMO1-gH/gL-gp42 complex revealed that AMMO1 binds to an epitope between D-I and D-II of $\mathrm{gH} / \mathrm{gL}^{24}$, which serves as a more precise target for future vaccine design and development. Recently, another human neutralizing antibody 769B10 was identified and found to compete for binding to $\mathrm{gH} / \mathrm{gL}$ with AMMO1 and CL40, although no structural information was available ${ }^{11}$.

In this work, we seek to isolate more neutralizing antibodies from EBV-infected individuals targeting the EBV gH/gL. After screening a large number of infected individuals, we successfully isolated the anti-gH/gL-antibody 1D8, which is capable of efficiently neutralizing EBV infection of epithelial cells and B cells in vitro. 1D8 also provides protection against EBV challenge in humanized mice by significantly reducing the viral loads and associated tumor burden. Using X-ray crystallography, we determine the structure of the 1D8-gH/gL complex and show that $1 \mathrm{D} 8$ recognizes a novel epitope located at the top of the groove between D-I and D-II of $\mathrm{gH} / \mathrm{gL}$, especially the D-II of $\mathrm{gH}$. Notably, this epitope is located on the opposite side of that recognized by AMMO1, CL40, and 769B10. In addition, 1D8 also significantly inhibit viral membrane fusion and $\mathrm{gH} / \mathrm{gL}$ binding to epithelial cell receptor EphA2. We believe that this new vulnerable site, together with that recognized by AMMO1, CL40, and 769B10, suggests that D-I and D-II represent an attractive target that is potentially important for antibody and vaccine intervention against EBV infection.

\section{Results}

Isolation of human monoclonal antibodies targeting the EBV gH/gL. We first screened plasma samples from a cohort of highrisk individuals and nasopharyngeal carcinoma patients ${ }^{48,49}$ for those with the highest levels of binding and neutralizing activity. Of the 48 plasma samples screened, donor 27 from the high-risk group had antibodies with the highest affinity for $\mathrm{gH} / \mathrm{gL}$ measured by ELISA, with the half-maximal effective concentration $\left(\mathrm{EC}_{50}\right)$ corresponding to a 6874-fold dilution (Supplementary Fig. 1a). The same plasma sample also displayed the most potent neutralizing activity against EBV infection of HNE1 epithelial cells and Raji B cells, with respective half-maximal inhibitory concentrations $\left(\mathrm{IC}_{50}\right)$ corresponding to a 273-fold and 1250-fold dilution (Supplementary Fig. 1b). To isolate monoclonal antibodies, we used phycoerythrin (PE) conjugated $\mathrm{gH} / \mathrm{gL}$ as baits to stain and sort the antigen-specific memory B cells from the peripheral blood mononuclear cells (PBMCs) of donor 27 using flow cytometry (Fig. 1a). Out of a total 54 sorted single B cells, we were able to clone and express 10 full-length human immunoglobulin G1 (IgG1) genes in transfected 293T cells. Two antibodies, 1D8 and $2 \mathrm{~A} 6$, were found to have strong binding to $\mathrm{gH} / \mathrm{gL}$. As shown in Fig. 1b, 1D8 showed $\sim 7$-fold stronger binding to $\mathrm{gH} / \mathrm{gL}$ than $2 \mathrm{~A} 6$, with concentration for $50 \%$ of maximal effect $\left(\mathrm{EC}_{50}\right)$ of $0.008 \mu \mathrm{g} / \mathrm{ml}$ and $0.057 \mu \mathrm{g} / \mathrm{ml}$, respectively. 1D8 also demonstrated higher neutralizing activity than 2A6 against EBV infection of HNE1 epithelial cells and Raji B cells (Fig. 1c, d and Supplementary Table 1 ). The $\mathrm{IC}_{50}$ of $1 \mathrm{D} 8$ was about 6 -fold lower than that of 2A6 for both cell types. Notably, 1D8 displayed comparable binding and neutralizing activities to AMMO1, a potent $\mathrm{gH} / \mathrm{gL}$ specific neutralizing antibody previously isolated from an EBVinfected individual ${ }^{24}$. The equilibrium dissociation constant (KD) measured by surface plasmon resonance (SPR) was $0.59 \mathrm{nM}$ for $1 \mathrm{D} 8$ and $0.14 \mathrm{nM}$ for AMMO1 (Supplementary Fig. 1c, d and 

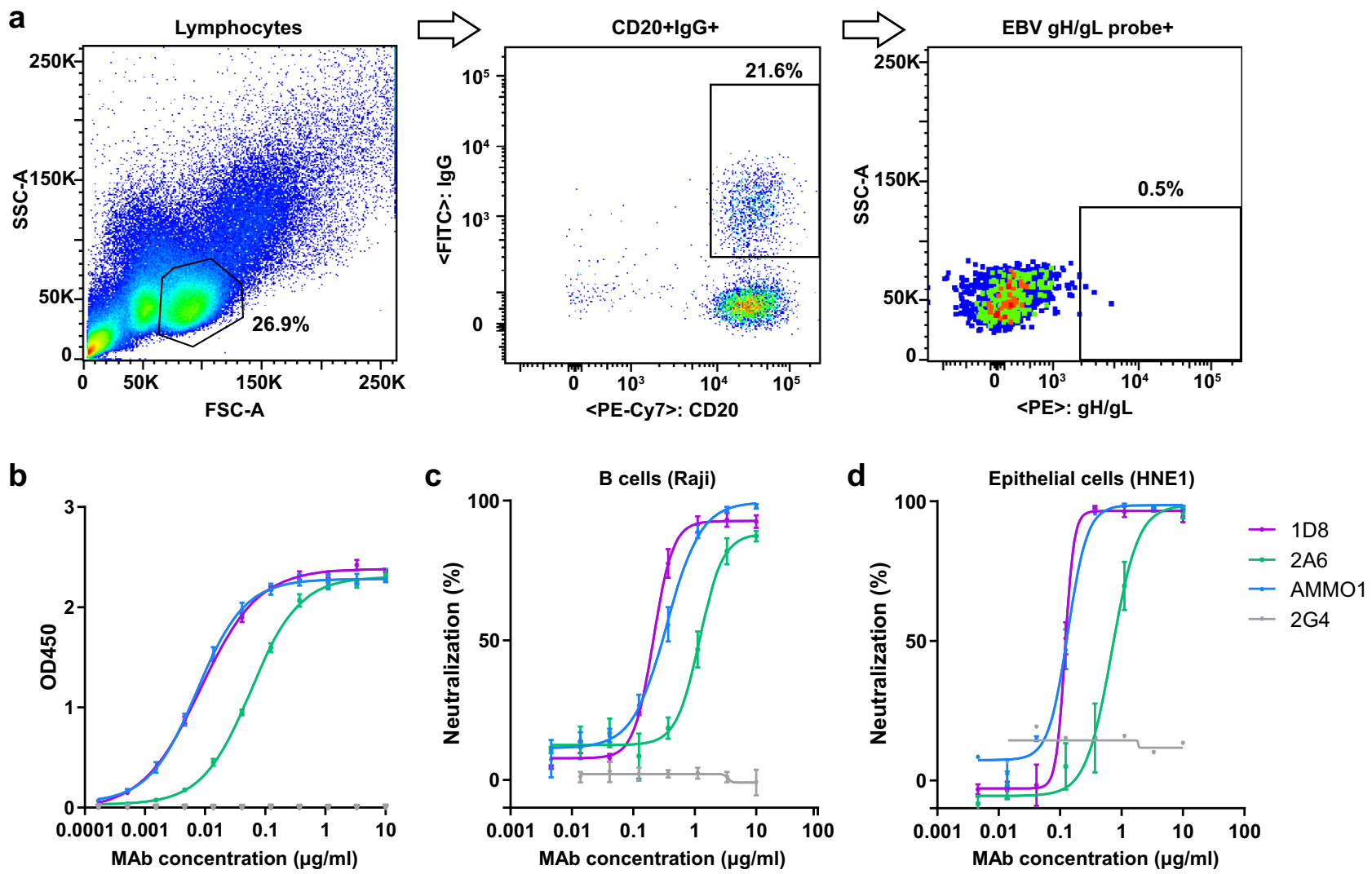

Fig. 1 Isolation of $\mathbf{g H / g L - s p e c i f i c ~ m o n o c l o n a l ~ a n t i b o d i e s ~ u s i n g ~ s i n g l e ~ B ~ c e l l ~ s o r t i n g ~ a n d ~ c l o n i n g . ~ a ~ F A C S - b a s e d ~ s o r t i n g ~ s t r a t e g y ~ f o r ~} g \mathrm{H} / \mathrm{gL}$-specific $\mathrm{B}$ cells. b Binding activities of 1D8 and 2A6, the positive control AMMO1, and the negative control 2G4 to EBV gH/gL measured by ELISA. The data are presented as means \pm SEM from two replicates. c Neutralizing activities of 1D8 and 2A6, the positive control AMMO1, and the negative control 2G4 against EBV infection of Raji B cell lines and (d) HNE1 epithelial cell line. The data shown are means \pm SEM from two replicates. SSC-A, side-scatter area; FSC-A, forward-scatter area. Source data are provided as a Source Data File.

Supplementary Table 2). When tested for neutralizing activity against EBV infection, $1 \mathrm{D} 8$ and $\mathrm{AMMO} 1$ showed $\mathrm{IC}_{50}$ values of $0.238 \mu \mathrm{g} / \mathrm{ml}$ and $0.318 \mu \mathrm{g} / \mathrm{ml}$ in Raji B cells, as well as $0.123 \mu \mathrm{g} / \mathrm{ml}$ and $0.127 \mu \mathrm{g} / \mathrm{ml}$ in HNE1 epithelial cells, respectively (Fig. 1c, d and Supplementary Table 1). Notably, neither 1D8 nor AMMO1 could completely block EBV infection in vitro. There were approximately $8 \%$ and $2 \%$ of Raji B cells, as well as $6 \%$ and $2 \%$ of HNE1 epithelial cells, were infected after treatment with $10 \mu \mathrm{g} / \mathrm{ml}$ of 1D8 and AMMO1, respectively (Fig. 1c, d). For neutralization in primary B cells, the $\mathrm{IC}_{50}$ of $1 \mathrm{D} 8$ and AMMO1 are $0.361 \mu \mathrm{g} / \mathrm{ml}$ and $0.227 \mu \mathrm{g} / \mathrm{ml}$, respectively. In Bmil-immortalized nasopharyngeal epithelial cell line (NPEC1-Bmi1) ${ }^{42}$, the $\mathrm{IC}_{50}$ of $1 \mathrm{D} 8$ and AMMO1 are $0.173 \mu \mathrm{g} / \mathrm{ml}$ and $\sim 10 \mu \mathrm{g} / \mathrm{ml}$, respectively.

$1 \mathrm{D8}$ protects against lethal EBV challenge in humanized mice. To test the protective potential of $1 \mathrm{D} 8$ in vivo, we used a humanized mouse model reconstituted with human cord bloodderived $\mathrm{CD} 34+$ stem cells that became susceptible to EBV infection and disease after approximately 8 weeks of development and maturation ${ }^{50-52}$. The entire experimental protocol and assays conducted to evaluate protection are outlined in Fig. 2a. Briefly, we administrated $400 \mu \mathrm{g}$ of 1D8, AMMO1 as positive control, or $2 \mathrm{G} 4^{53}$ and PBS as negative controls to groups of seven to eight humanized mice via the intraperitoneal (i.p.) route. On the following day, the animals were challenged with 1000 50\% transforming dose $\left(\mathrm{TD}_{50}\right)$ Akata $\mathrm{EBV}$ via the intravenous (i.v.) route. In the ensuing up to 6-week period, all animals received the testing antibodies or PBS weekly via the i.p. route and were monitored for body weight, survival, as well as various virologic and immunologic parameters.

EBV DNA in the peripheral blood measured by quantitative PCR reflected the distinctions in clinical manifestation between these animals (Fig. 2b). In the animals treated with 1D8 and AMMO1, EBV DNA became detectable on week 3 after challenge and slowly increased in the following two weeks, but no animals had EBV DNA copy numbers greater than 10 copies/ $\mu$ l blood at week 5 post-challenge. By contrast, in the animals treated with 2G4 and PBS, EBV DNA rapidly increased from week 3 onwards after the challenge and reached about 100-fold higher copy numbers than 1D8 and AMMO1 treated animals at week 5 postchallenge (Fig. 2b). All animals in the 1D8 and AMMO1 treated groups survived the challenge and demonstrated relatively stable body weight without obvious pathology (Fig. 2c, d). By contrast, negative control animals (2G4 and PBS groups) began significantly losing weight starting on day 28 (4 weeks), succumbed to disease and had to be euthanized by day 38 after the challenge.

By the time they were ready for the protection experiments, the reconstituted animals had about $20 \%$ human CD $45+$ lymphocytes in the peripheral blood, nearly $90 \%$ of which were human $\mathrm{CD} 20+\mathrm{B}$ cells and $<1 \%$ were human CD3 $+\mathrm{T}$ cells (Fig. $2 \mathrm{e}-\mathrm{g}$ ). In addition, the dynamic change of human CD20+CD $45+\mathrm{B}$ cells and $\mathrm{CD} 3+\mathrm{CD} 45+\mathrm{T}$ cells in the peripheral blood was correlated with distinct pattern of disease progression between these animals. Animals in the 1D8 and AMMO1 treated groups showed a relatively slower decrease in the percentage of CD20+CD45 + B cells compared with the 2G4 and PBS treated 


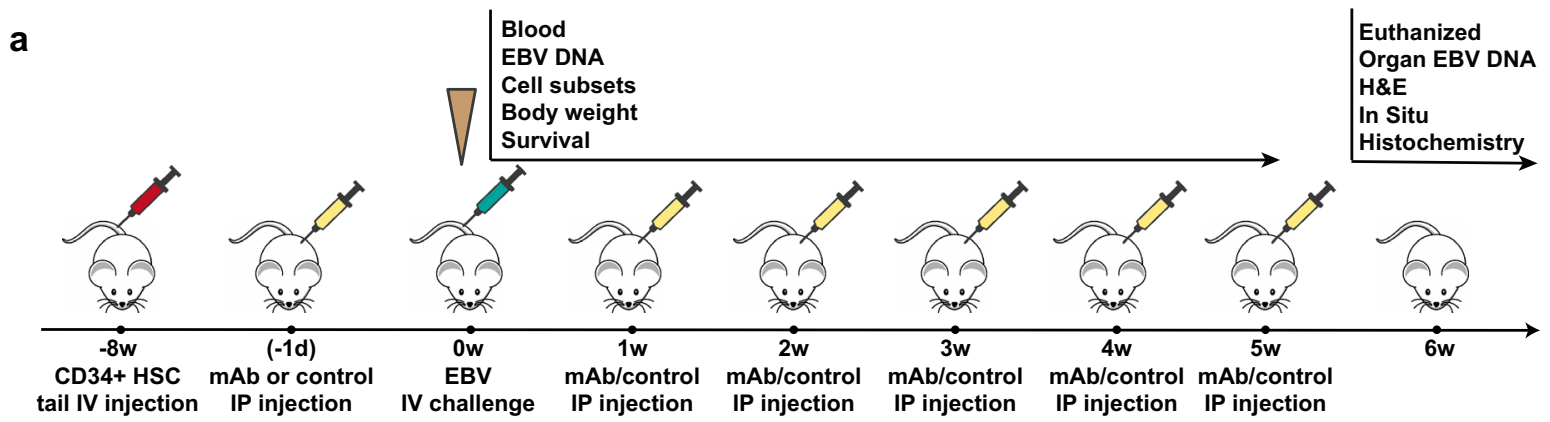

b

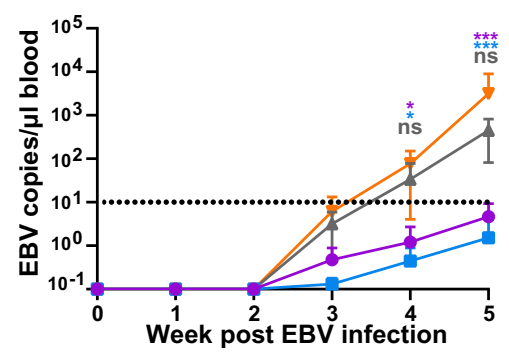

e

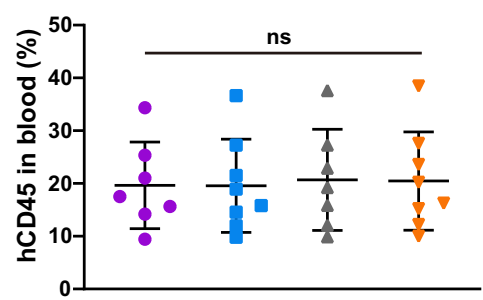

\section{h}

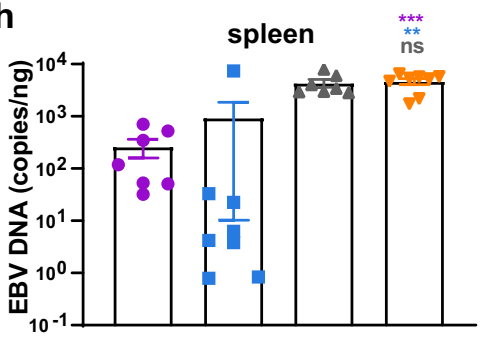

C

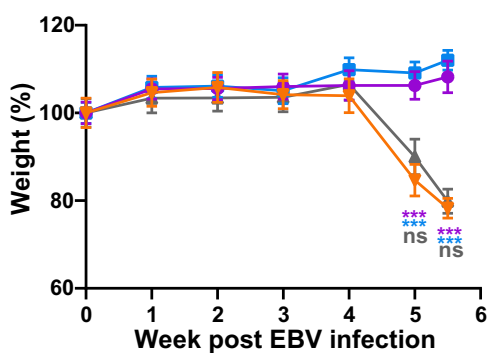

f

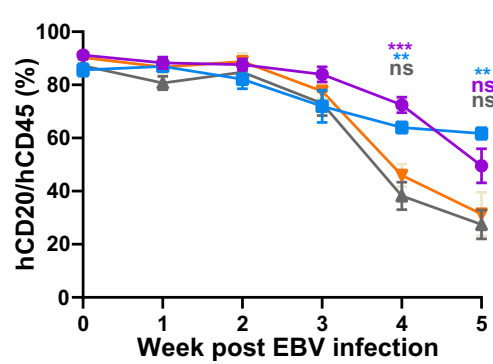

i

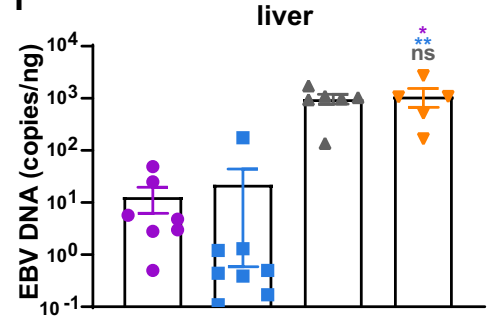

d

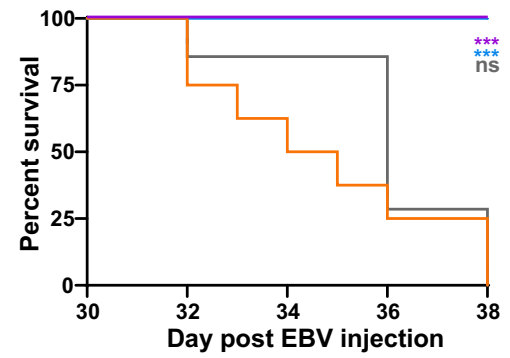

g

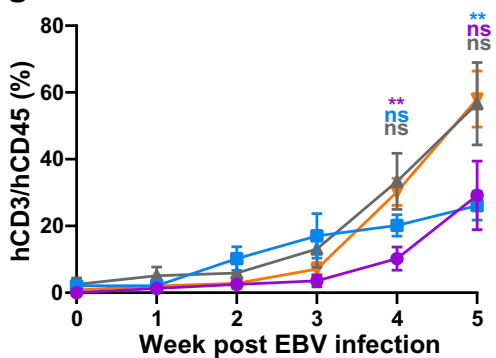

j

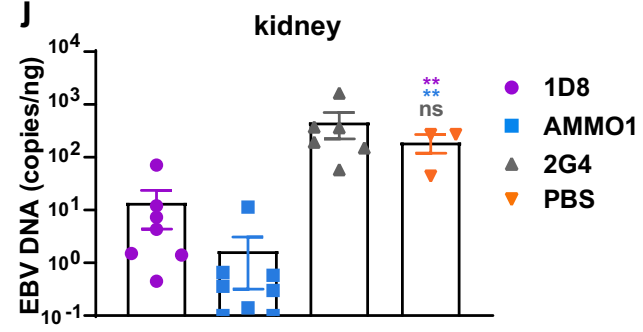

Fig. 2 Protective efficacy of 1D8 against lethal EBV challenge in humanized mice. a Timeline for engrafting CD34 + human hematopoietic stem cells (HSC), antibody administration, viral challenge, and monitoring for various biological and clinical outcomes. $400 \mu \mathrm{g}$ of 1D8 ( $n=7$ ), positive control AMMO1 $(n=8)$, negative control 2G4 $(n=7)$, or PBS $(n=8)$ were administered to the humanized mice via intraperitoneal injection either $24 \mathrm{~h}$ prior to or weekly for 5 weeks after intravenous challenge with Akata EBV. b EBV DNA in the peripheral blood, (c) body weight, and (d) survival were monitored weekly. The percent changes in (e) hCD45 +, (f) hCD20 +, or (g) hCD3+ cells over the experiment period. On week 6 post infection, (h) virus titers in spleen, (i) liver, (j) kidney were analyzed. All data are presented as mean \pm SEM. ${ }^{\star} p<0.05 ;{ }^{\star \star} p<0.01$; ${ }^{\star \star \star} p<0.001$; ns, no significant, two-tailed unpaired Student's $t$ test. (b) $1 \mathrm{D} 8$ vs PBS in $4 \mathrm{w}^{\star} p=0.017$, AMMO1 vs PBS in $4 \mathrm{w}^{\star} p=0.010,{ }^{\star \star \star} p<0.0001 ;(\mathbf{c}){ }^{\star \star \star} p<0.0001$; (d) $1 \mathrm{D} 8$ vs PBS ${ }^{\star \star \star} p=0.0002$, AMMO1 vs PBS ${ }^{\star \star \star} p=0.0004$, log-rank test (Mantel-Cox); (f) 1 D8 vs PBS in 4w ${ }^{\star \star \star} p=0.0003$, AMMO1 vs PBS in $4 w^{\star \star} p=0.0021$, AMMO1 vs PBS in $5 w^{\star \star} p=0.001 ;(\mathbf{g}) 1 \mathrm{D} 8$ vs PBS in $4 w^{\star \star} p=0.0028$, AMMO1 vs PBS in $5 w^{\star \star} p=0.0034 ;(\mathbf{h}){ }^{\star \star \star} p<0.0001,{ }^{\star \star} p=0.0048 ;(\mathbf{i}){ }^{\star} p=0.0126,{ }^{\star \star} p=0.008$; (j) $1 \mathrm{D} 8$ vs $\mathrm{PBS}{ }^{\star \star} p=0.0052, \mathrm{AMMO1}$ vs PBS ${ }^{\star *} p=0.0013$. Source data are provided as a Source Data File.

groups. As a result, the slower increase in percentage of $\mathrm{CD} 3+\mathrm{CD} 45+\mathrm{T}$ cells was noticed in this group of animals compared to those treated by $2 \mathrm{G} 4$ and PBS (Fig. $2 \mathrm{f}$, g). Of note, these cells are unlikely virus-specific but mainly represent the process of reconstitution ${ }^{54}$.

Furthermore, EBV DNA copy numbers measured in the spleen, liver and kidney collected at necropsy shared a similar trend with those measured in the peripheral blood (Fig. $2 \mathrm{~h}-\mathrm{j}$ ). The copy numbers of EBV DNA were significantly lower in the $1 \mathrm{D} 8$ and AMMO1 treated groups than in the 2G4 and PBS treated groups, although the copy numbers were generally higher in the spleen than in the liver and kidney (Fig. 2h-j).

We also conducted a similar experiment in humanized mice to test whether a single dose of antibody could reduce the burden of tumors caused by EBV infection. As shown in Supplementary Fig. 2a, we administrated $400 \mu \mathrm{g}$ of antibodies or PBS to humanized mice. The next day, animals were challenged with 1,000 $\mathrm{TD}_{50}$ Akata EBV. All animals were monitored for body weight, survival, as well as virologic parameters up to 7 weeks. In the $1 \mathrm{D} 8$ and AMMO1 treated groups, EBV DNA in peripheral 
blood was significantly lower than that in the control groups (Supplementary Fig. 2b). Meanwhile, all animals in 1D8 and AMMO1 treated groups survived the challenge, maintained stable body weight and had lower spleen weight collected at necropsy (Supplementary Fig. 2c-e). Furthermore, EBV DNA copy numbers measured in spleen, liver, and kidney were also lower in 1D8 than the control groups, and in AMMO1 than the control groups. However, comparing between AMMO1 and 1D8 treated groups, the EBV levels were significantly lower only in the spleen while quite comparable in the liver and kidney (Supplementary Fig. 2f-h).

Taken together, these results demonstrated that 1D8 as well as the positive control AMMO1 might reduce EBV replication and, to a certain extent, provide protection from a lethal EBV challenge.

Marked reduction in viral replication and tissue damages in the protected animals. To study the impact of protection at the tissue levels, we collected the spleen, liver and kidney of the animals at the necropsy. The most profound and visible changes were observed in the spleens. Morphologically, the spleens from the 2G4 and PBS groups were clearly enlarged with a few irregular and pale tumors across the entire surface. By contrast, the spleens in the 1D8 and AMMO1 groups were normal in size and color, without visible tumors (Fig. 3). We went on to perform histopathology analysis on the spleen sections using hematoxylin and eosin (H\&E) staining, immunohistochemistry (IHC) for hCD3 and hCD20, as well as in situ hybridization for Epstein-Barr virusencoded RNAs (EBERs) (Fig. 3). All mice treated with 2G4 or PBS presented with typically large B-cell lymphomas in the white pulp regions, which were positive for hCD20 and EBER. They were abundant and widely distributed across the tissue sections. Morphologically their proliferations destroyed the underlying architecture of the tissue with some infiltration by hCD3 $+\mathrm{T}$ cells. Additionally, areas of coagulative necrosis were often present in the spleens of mice from the 2G4 and PBS groups. By contrast, in the 1D8 and AMMO1 groups, the overall tissue architecture remained largely intact, even if some atypical large transformed cells could also be seen. Among the large number of hCD20+ B cells in the white pulp areas, EBER + cells were relatively fewer compared to the PBS and 2G4 treated groups. A number of $\mathrm{hCD} 3+\mathrm{T}$ cells were also found scattered within. Similarly, in the hepatic and renal sections from 2G4 and PBS groups, a large number of hCD20+ and EBER + B cells were identified, while they were rare in the 1D8 and AMMO1 groups (Supplementary Fig. 3). The infected cells were frequently found near the blood vessels in both the liver and kidney, likely the results of migration and seeding from the blood circulation. Collectively, these results show that 1D8 and AMMO1 can significantly reduce viral replication and tissue damage relative to 2G4 and PBS, offering an explanation for their in vivo protection against a lethal EBV challenge.

$1 \mathrm{D8}$ binds to a novel epitope on $\mathrm{gH} / \mathrm{gL}$. To understand the neutralizing mechanism of $1 \mathrm{D} 8$, we sought to determine the structure of the $1 \mathrm{D} 8-\mathrm{gH} / \mathrm{gL}$ complex by X-ray crystallography. After screening nearly 100 crystals with relatively weak diffraction, we obtained a dataset with 4.2 angstrom resolution and solved the structure by molecular replacement (Supplementary Table 3). 1D8 was found to bind to the interface at the top of the groove formed by D-I and D-II of gH/gL, especially the D-II of gH (Fig. 4a). While CDRL1, CDRL3 and CDRH2 made negligible contribution, CDRL2, CDRH1 and CDRH3 interacted substantially with $\mathrm{gH}$ and gL. CDRL1 interacted with gH largely through $2 \alpha-2$ and $2 \beta-2$ whereas CDRH1 and CDRH 3 through the loop between $2 \alpha-9$ and $2 \beta-11$. CDRH3 also bound to the loop between $2 \alpha-1$ and $2 \beta-1$ of $\mathrm{gH}$. The heavy chain of 1D8 was also found to interact with gL through the loop between $\mathrm{L} \alpha-1$ and $\mathrm{L} \alpha$ 2 (Fig. 4b). To study the locality and topology of 1D8 recognition relative to that of AMMO1, we went further to collect $\sim 5000$ cryo-EM images of the $\mathrm{gH} / \mathrm{gL}$ bound to the 1D8 Fab and the AMMO1 Fab (Supplementary Fig. 4a). While the data was

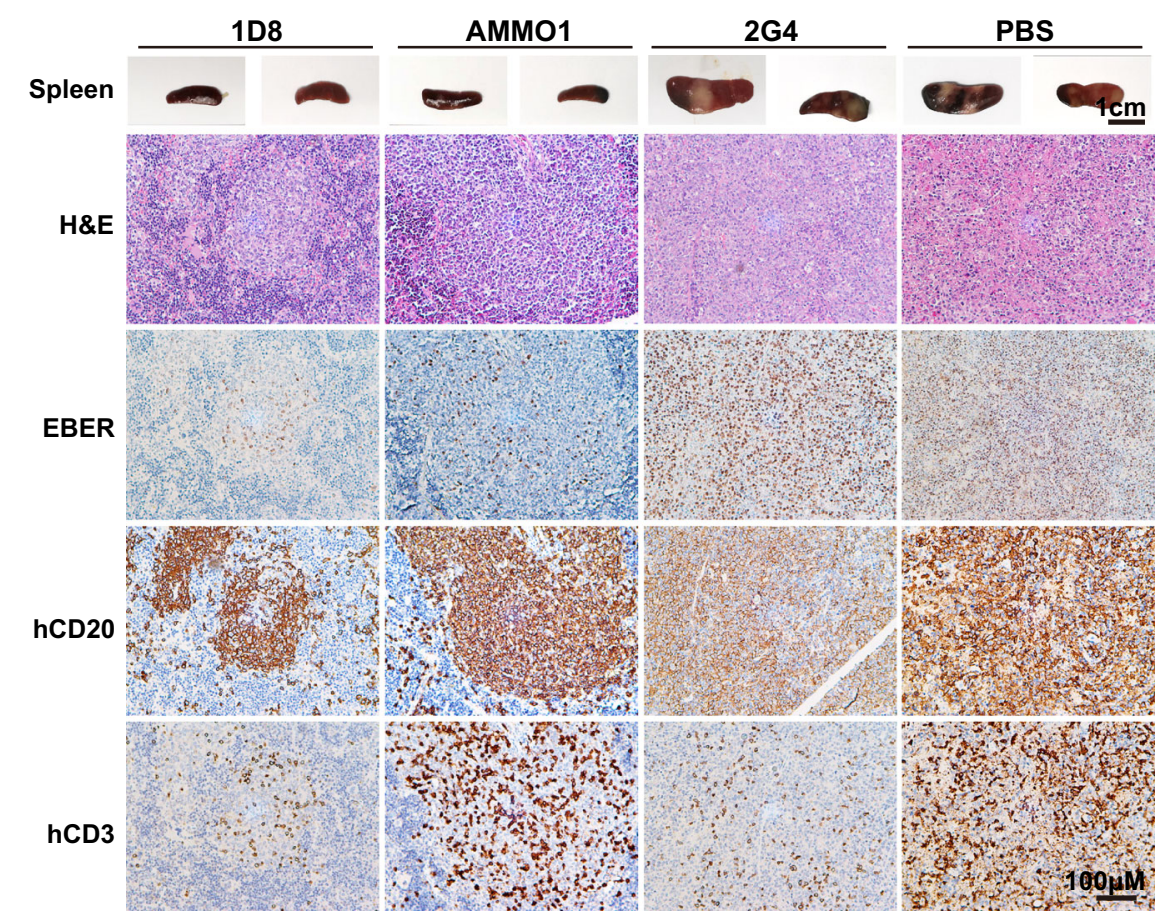

Fig. $31 D 8$ reduces viral replication and tissue damages in humanized mice. Representative of macroscopic spleens and splenic sections stained for hematoxylin and eosin (H\&E), EBV encoded RNA (EBER), human CD20 (hCD20), and human CD3 (hCD3) at necropsy. The scale bars are indicated. Each image is representative of a group of 7-8 mice. 

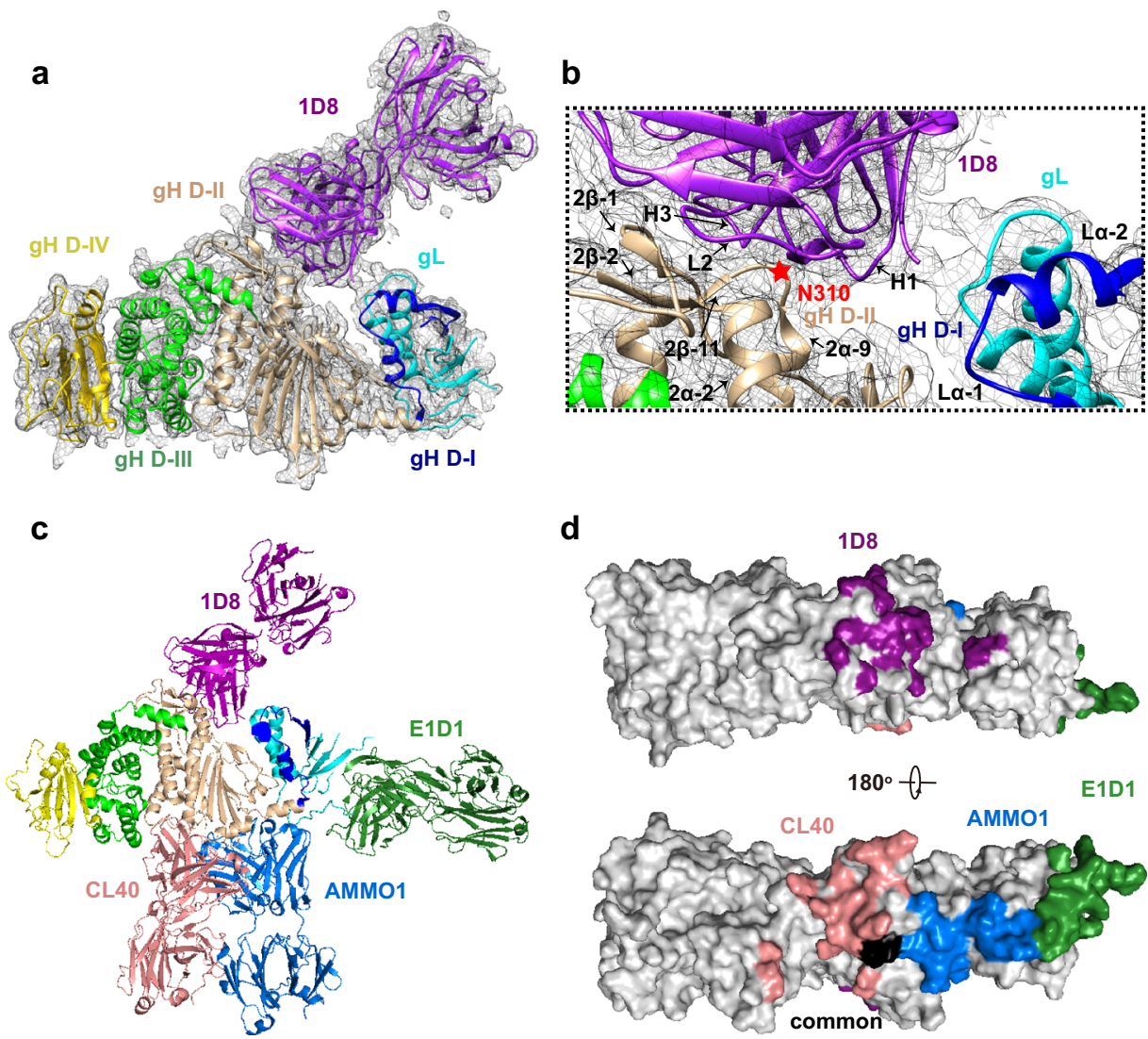

Fig. 41 D8 targets a novel epitope on gH/gL. a Structure overview in a cartoon representation with gL in cyan, gH D-I in blue, D-II in wheat, D-III in green, D-IV in yellow, and 1D8 Fab in purple. The map is contoured at 1.2 RMS to show the density. $\mathbf{b}$ Zoomed-in view of the interaction between 1D8 and D-I and D-II. The key binding residue N310 of gH was indicated by a red star. c Cartoon representation of Fab $1 \mathrm{D} 8$ and other previously published Fabs AMMO1, $\mathrm{CL} 40$, and E1D1 bound to a single $\mathrm{gH} / \mathrm{gL}$ molecule. The color scheme for $\mathrm{gH} / \mathrm{gL}$ is as in (a) whereas 1D8 Fab in purple, AMMO1 Fab in light blue, CL40 Fab in pink, and E1D1 Fab in dark green. $\mathbf{d}$ Surface mapping of the four Fab epitopes on gH/gL with the same color in (c). Areas in black indicate the region where structural change was found upon binding to AMMO1 or CL40.

inadequate to obtain 3D density map for model building, we managed to build a 2D model of the gH/gL-1D8-AMMO1 ternary complex (Supplementary Fig. 4 b) by superimposing the crystal structure of $\mathrm{gH} / \mathrm{gL}-1 \mathrm{D} 8$ onto the previously reported $\mathrm{gH} /$ gL-gp42-AMMO1 complexes ${ }^{24}$. The calculated projection of the $\mathrm{gH} / \mathrm{gL}-1 \mathrm{D} 8$-AMMO1 model matched well with the 2D average of gH/gL-1D8-AMMO1 single-particle cryo-EM data (Supplementary Fig. 4a, b). This result further validated the structural features of the $\mathrm{gH} / \mathrm{gL}-1 \mathrm{D} 8$ crystal structure and demonstrated that epitope of the $1 \mathrm{D} 8$ is distinct from that AMMO1. Of note, as the 4.2 angstrom resolution was insufficient to determine the side chain interaction at the interface, the above interpretations need to be taken with caution.

Furthermore, to identify the key residue for antibody binding, we generated a series of single alanine substitutions for the contacting residues on $\mathrm{gH} / \mathrm{gL}$. As 4.2 angstrom resolution is not high enough to resolve the side chains, we increased the distance cutoff from 4 to 6 angstrom to include all potential contacting residues. Except for two (L122A and C312A), the remaining 27 mutants were successfully expressed in the supernatant of transfected $293 \mathrm{~F}$ cells. We then performed ELISA to assess the impact of these mutants on 1D8 binding. One mutant, N310A, located in the loop between $2 \alpha-9$ and $2 \beta-11$ of $\mathrm{gH}$, was identified to specifically reduce the binding of $1 \mathrm{D} 8$ but not AMMO1 (Fig. $4 \mathrm{~b}$ and Supplementary Fig. 5a, b). When measured by SPR, the binding affinity of $1 \mathrm{D} 8$ to this mutant dropped to $31.6 \mathrm{nM}$, representing more than 53 -fold decrease from the $0.59 \mathrm{nM}$ of the wild type $\mathrm{gH} / \mathrm{gL}$. However, no significant change of binding was found for AMMO1 compared to the wild type $\mathrm{gH} / \mathrm{gL}$ ( $0.14 \mathrm{nM}$ vs. $0.19 \mathrm{nM}$ ) (Supplementary Fig. 5c, d and Supplementary Table 2). We are uncertain why only $\mathrm{N} 310 \mathrm{~A}$ resulted in substantial reduction in binding while the impacts of the remaining 26 mutants were rather minimal. It is possible that multiple mutations are required to work in concert to effectively disrupt $1 \mathrm{D} 8$ recognition, given its potent binding activity of $0.59 \mathrm{nM}$ to $\mathrm{gH} / \mathrm{gL}$ measured by SPR. Alternatively, as the structure resolution was relatively low, our predication on the epitope residues were not as entirely precise as expected. Further studies would be warranted to resolve this uncertainty.

The unique binding mode of 1D8 is further supported by superimposing the antibodies with known structural information onto the same gH/gL molecule. As shown in Fig. 4c, d, 1D8 binds to $\mathrm{gH} / \mathrm{gL}$ at the top of the groove formed between D-I and D-II, especially the D-II of $\mathrm{gH}$, while AMMO1 binds to the opposite side of the molecule through a discontinuous epitope formed at the D-I/D-II interface. The mouse-derived antibody CL40 partially overlaps with the epitope of AMMO1 by binding to an epitope on $\mathrm{gH}$ at the interface between D-II and D-III ${ }^{24}$. A recently isolated human mAb 769B10 also competed for $\mathrm{gH} / \mathrm{gL}$ binding with AMMO1 and CL40, indicating a shared vulnerable site for neutralization ${ }^{11}$. Another mouse antibody E1D1, however, only recognizes $\mathrm{gL}^{39,47}$ (Fig. 4c, d). Lastly, we used bio-layer interferometry (BLI) to confirm that 1D8 does not compete with any of these antibodies in binding to $\mathrm{gH} / \mathrm{gL}$ (Supplementary Fig. 5e). Collectively, these results indicate that $1 \mathrm{D} 8$ recognizes a novel vulnerable site on $\mathrm{gH} / \mathrm{gL}$ and provide a good rationale for 
a

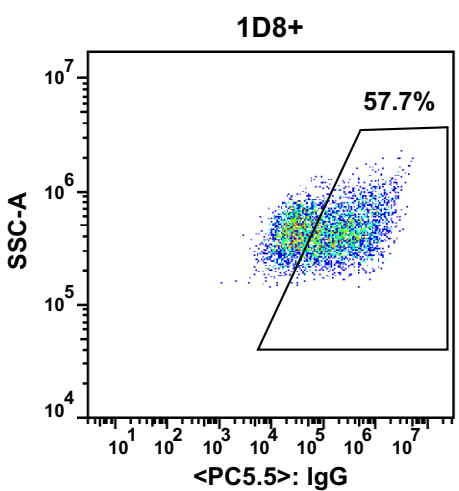

d

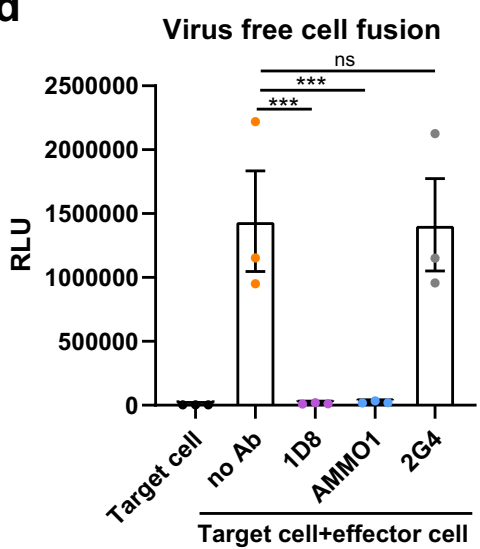

g

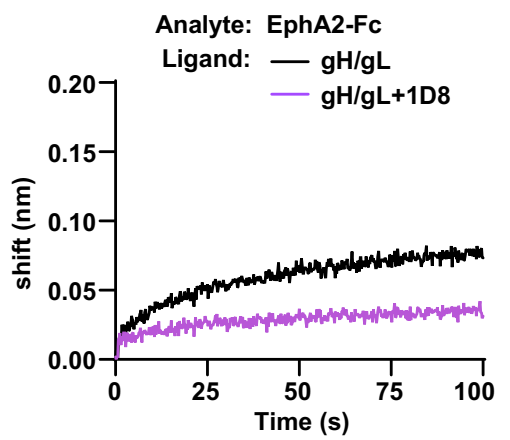

b

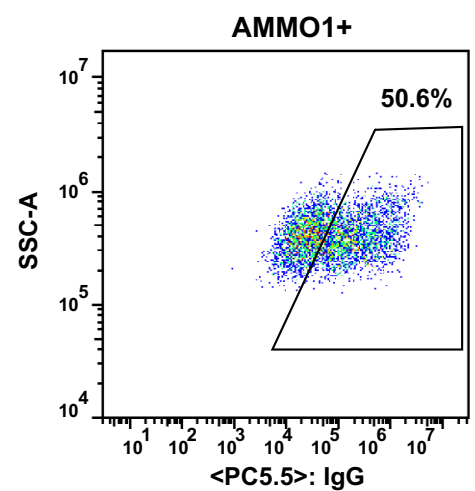

e

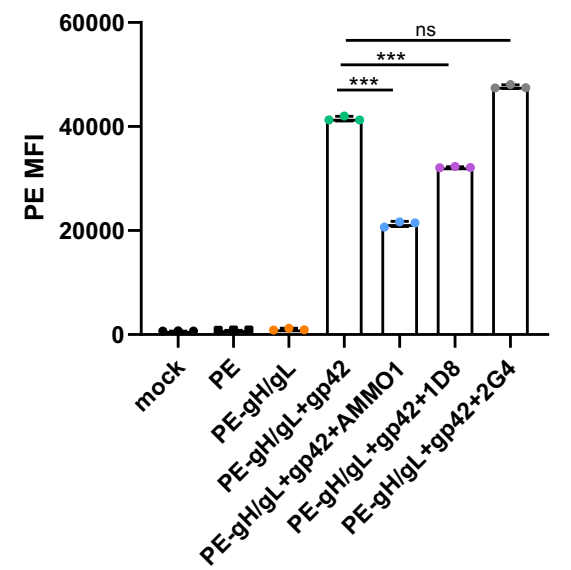

h

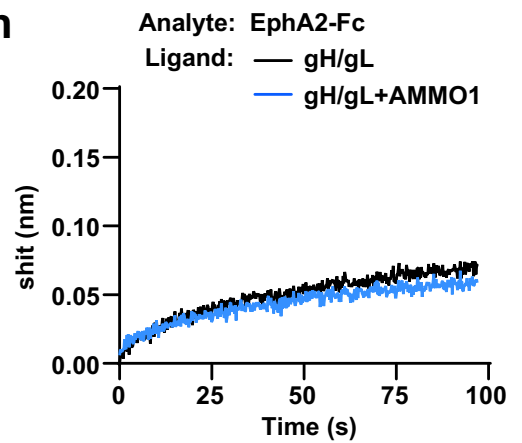

C

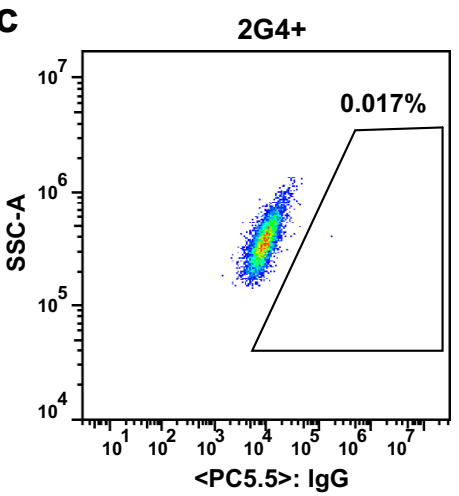

f

f Binding to epithelial cells (HK1)
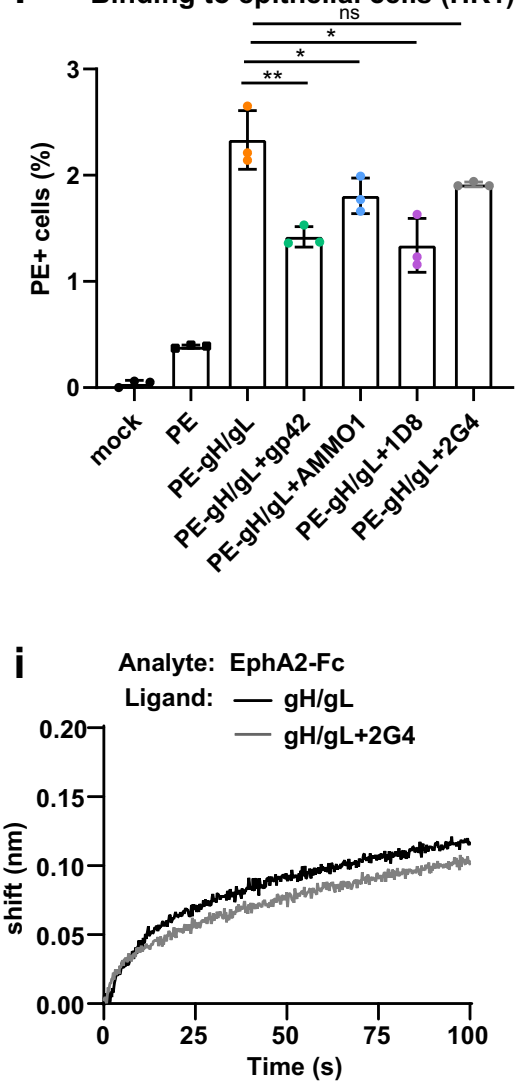

Fig. 51 D8 interferes with cell fusion and binding. Quality control of $\mathrm{gH} / \mathrm{gL}$ expression on the surface of $\mathrm{CHO}-\mathrm{K} 1$ cells by staining with $1 \mathrm{D} 8$ (a), positive control AMMO1 (b), and negative control 2G4 (c) before proceeded to the fusion experiment shown in (d). d Marked reduction in cell-cell fusion in the presence of 1D8, the positive control AMMMO1, but not the negative control 2G4. Marked reduction in $\mathrm{gH} / \mathrm{gL}$ binding to Raji B cell (e) and HK1 epithelial cell (f) in the presence of 1D8, the positive control AMMO1, but not the negative control 2G4. Binding of EphA1-Fc to gH/gL was reduced by 1D8 (g), but not by AMMO1 (h) or $2 \mathrm{G} 4$ (i) measured by BLI. All data are presented as mean \pm SEM from three replicates. ${ }^{\star} p<0.05 ;{ }^{* \star} p<0.01 ;{ }^{* \star *} p<0.001 ;$ ns, no significant; two-tailed unpaired Student's $t$ test. $\mathbf{d}{ }^{\star \star \star} p<0.0001$; (e) ${ }^{\star \star \star} p<0.0001$; (f) gp42 ${ }^{\star \star} p=0.0057$, AMM01 ${ }^{\star} p=0.0478,1$ D8 ${ }^{\star} p=0.010$. SSC-A, side-scatter area; PC5.5, PerCP-Cy5.5; RLU, relative light unit; SA-PE, streptavidin-phycoerythrin; MFI, mean fluorescence intensity. Source data are provided as a Source Data File.

the combined use with other antibodies to improve inhibition of EBV infection.

1D8 inhibits $\mathrm{gH} / \mathrm{gL}$-mediated membrane fusion and binding to $B$ and epithelial cells. We next studied the ability of $1 \mathrm{D} 8$ to inhibit gH/gL-mediated membrane fusion by monitoring the fusion efficiency between the effector and target cells. Specifically, effector $\mathrm{CHO}-\mathrm{K} 1$ cells expressing the $\mathrm{gH} / \mathrm{gL}$ and $\mathrm{gB}$ fusion machinery were incubated with a saturated concentration of 1D8 or relevant controls at $37^{\circ} \mathrm{C}$ for $1 \mathrm{~h}$ before mixing at a 1:1 ratio with the target HEK293 cells. The inhibitory activity was measured $24 \mathrm{~h}$ afterwards via the luciferase activity in the cell lysates, which only became detectable when fusion occurred. As shown in Fig. 5a-c, the effector CHO-K1 cells expressed good levels of gH/ $\mathrm{gL}$ as measured by flow cytometry. In the presence of 1D8 or AMMO1, the fusion activity was barely measurable and similar to the background where only the effector cells were present (Fig. 5d). By contrast, incubation with the negative controls 2G4 or PBS resulted in high levels of luciferase activity beyond one million relative light unit (RLU). In addition, we tested the ability of 1D8 to interfere with the binding of fluorescently labeled 
$\mathrm{gH} / \mathrm{gL}$ to Raji B cells and HK1 epithelial cells, both of which are susceptible to EBV infection in vitro ${ }^{55,56}$. Gp42 was included in the assessment of the binding to $\mathrm{B}$ cells but not for the epithelial cells, since the $\mathrm{gH} / \mathrm{gL}-\mathrm{gp} 42$ complex is specifically required for $\mathrm{B}$ cell activation and fusion ${ }^{39}$. 1D8 and relevant controls were incubated with fluorescent-labeled $\mathrm{gH} / \mathrm{gL}$ at $37^{\circ} \mathrm{C}$ for $1 \mathrm{~h}$ before mixing with $\mathrm{B}$ cells or epithelial cells and further incubation on ice for $1 \mathrm{~h}$. The levels of inhibition of $\mathrm{gH} / \mathrm{gL}$-mediated binding to both cell types were measured by flow cytometry. As shown in Fig. 5e, pre-incubation with 1D8 and AMMO1 significantly reduced but did not completely abrogate $\mathrm{gH} / \mathrm{gL}$-gp42 binding to $\mathrm{B}$ cells. While no difference was found between the negative controls 2G4 and PBS, AMMO1 appeared to be more potent than $1 \mathrm{D} 8$ in interfering with the binding of $\mathrm{gH} / \mathrm{gL}$ to $\mathrm{B}$ cells. Conversely, 1D8 seems to be more powerful than AMMO1 in inhibiting the binding of $\mathrm{gH} / \mathrm{gL}$ to the epithelial cells, whereas the negative controls showed negligible effect (Fig. 5f). Lastly, we studied the ability of 1D8 to inhibit the interaction between $\mathrm{gH} /$ gL and EphA2, a recently identified receptor for EBV infection of epithelial cells that depends on an interaction with $\mathrm{gH} / \mathrm{gL}^{43,44}$. Consistent with an earlier report ${ }^{24}$, the interaction between EphA2-Fc and $\mathrm{gH} / \mathrm{gL}$ was indeed rather weak as measured by BLI. Nevertheless, pre-incubation of gH/gL with $1 \mathrm{D} 8$ did result in a small and clear reduction in the interaction between $\mathrm{gH} / \mathrm{gL}$ and EphA2 (Fig. 5g). Conversely, such an effect was not noticed for AMMO1 or 2G4 (Fig. 5h, i). This may explain why 1D8 was more effective than AMMO1 in inhibiting EBV infection of epithelial cells (see above), although the underlying mechanism warrants further investigation. Taken together, these findings indicate that 1D8 as well as the positive control AMMO1 can significantly inhibit $\mathrm{gH} / \mathrm{gL}$-mediated membrane fusion and binding to $\mathrm{B}$ and epithelial cells, either through direct blocking of binding or by sterically interfering with the downstream interactions required for EBV infection.

\section{Discussion}

Neutralizing antibodies exert their function by targeting vulnerable sites on the viral envelope glycoproteins. Identifying the neutralizing $\mathrm{mAbs}$ and their recognized epitopes is therefore the first crucial step for understanding the protective antibody response, which can inform the rational development of antibody-based therapy and vaccines ${ }^{19,20}$. In some EBV-infected individuals, high levels of serum neutralizing antibodies have been identified capable of blocking infection of both B cells and epithelial cells ${ }^{11}$. This finding indicates that the human immune system can generate potent neutralizing antibodies to clear the infection and/or attenuate disease progression. However, the antigen and epitope specificity, as well as the potential mechanism of neutralization of these antibodies are not entirely clear.

We report here the isolation and characterization of the human neutralizing antibody 1D8, which substantially reduces infection of $B$ cells and epithelial cells in vitro. Passive delivery of 1D8 significantly reduced the viral loads and tumor burden of EBV-induced lymphoma in humanized mice. Structural analysis of the 1D8-gH/gL complex identified a novel epitope at the top groove of $\mathrm{gH} / \mathrm{gL}$ between D-I and D-II, especially the D-II of $\mathrm{gH}$, which is distinct from any of the reported antibodies. In addition, 1D8 was found to inhibit viral membrane fusion and reduce the binding of $\mathrm{gH} / \mathrm{gL}$ to the epithelial cell receptor EphA2 ${ }^{43,44}$. We believe that this new vulnerable site, together with that recognized by AMMO1, CL40, and 769B10, suggests that D-I and D-II represent an attractive target that is potentially important for antibody and vaccine intervention against EBV infection.

A couple of points need to be highlighted here. First, as both B cells and epithelial cells are major targets for EBV infection ${ }^{57}$, it is highly desirable to isolate neutralizing antibodies capable of blocking the virus and protecting both cell types from infection. $1 \mathrm{D} 8$, together with recently reported $\mathrm{AMMO}^{24}$ and $769 \mathrm{~B} 10^{11}$, are three representatives of this class of human antibodies with dual tropism. However, we are uncertain how much this type of antibodies contributes to the overall neutralizing activities in the infected individuals. Given the low frequency in identifying 1D8, AMMO1 and 769B10 antibodies among the isolated memory B cells $^{24}$, it is reasonable to assume they are quite rare and might only be induced among a small proportion of naturally infected patients. Compared to gp350, $\mathrm{gH} / \mathrm{gL}$ is much less abundant and therefore has a quantitative disadvantage in immune recognition and stimulation ${ }^{21}$. However, identification of 1D8, AMMO1, and 769B10 epitopes around D-I and D-II offer an unprecedented opportunity to expose this vulnerable site in much more precise and persistent manner so that more focused and stronger immune response like 1D8, AMMO1, and 769B10 could be generated. This could be done either by including $\mathrm{gH} / \mathrm{gL}$ in the vaccine regimen ${ }^{11,25}$ or singling out D-I and D-II domain as epitope-focused immunogens. Both approaches would require careful design and validation to ensure proper structure and exposure of vulnerable sites recognized by like 1D8, AMMO1, and 769B10. In support of this notion, nanoparticles displaying $\mathrm{gH} / \mathrm{gL}$ elicited a strong neutralizing antibody response against EBV infection of both target cell types ${ }^{11}$, even if this exciting report requires further confirmation. Lastly, given the relatively conserved nature of this region among herpesviruses ${ }^{27,30}$, carefully designed D-I and D-II immunogens may be able to induce an even broader and stronger cross-neutralizing antibody response against a wide variety of viral strains.

Second, despite structural and functional insights, we are still uncertain of the exact mechanism through which 1D8 neutralizes EBV infection of both target cell types. Structurally, although 4.2 angstrom resolution was insufficient to determine the atomic interaction at the interface, 1D8 recognized a novel epitope within the groove between D-I and D-II, especially the D-II of $\mathrm{gH}$. AMMO1, on the other hand, was found to bind a discontinuous epitope spanning D-I and D-II on the opposite ridge of the groove $^{24}$ whereas $769 \mathrm{~B} 10$ was found to compete with AMMO1 ${ }^{11}$. Such convergence on D-I and D-II domains suggests a common mechanism of neutralization, either by affecting coordination within and across D-I and D-II or their interaction with other viral glycoproteins such as $\mathrm{gB}$ or gp42 required for downstream viral entry (Fig. 6a, b). AMMO1 was postulated to lock D-I, D-II and the linker helix, preventing proper movement required for interaction and activation of $\mathrm{gB}^{58}$. As residues with the D-I and D-II groove also mediate membrane fusion and several of these critical residues are near the epitope of $1 \mathrm{D} 8^{33,34,58,59}$, it stands to reason that $1 \mathrm{D} 8$ could also exert its neutralization activity by inhibiting the fusion process. Instead of acting like a molecular clamp as AMMO1, 1D8 may act more like a molecular wedge forcing into the space within the groove. Certainly, as 1D8 and AMMO1 and 769B10 bind distinct epitopes, there must be some differences in the exact mechanisms underlying their inhibitory effects. For example, AMMO1 appears to be more potent than $1 \mathrm{D} 8$ in interfering with the binding of $\mathrm{gH} / \mathrm{gL}$ to B cells (Fig. $5 \mathrm{e}$ ), perhaps due to its ability to displace the c-terminal domain of gp42 through the gp42 N173 glycan ${ }^{24}$. Conversely, 1D8 seems to be more powerful than AMMO1 in inhibiting binding of $\mathrm{gH} / \mathrm{gL}$ to epithelial cells, likely by affecting the interaction between EphA2-Fc and gH/gL (Figs. 5f, g and 6a). In any case, the 1D8 antibody identified in this study represents another potent human neutralizing antibody that can be used alone or in combination with other antibodies such as AMMO1 and 769B10 for antibodybased interventions against EBV infection. The epitope defined here will also assist the rational design of vaccines focusing more 
a

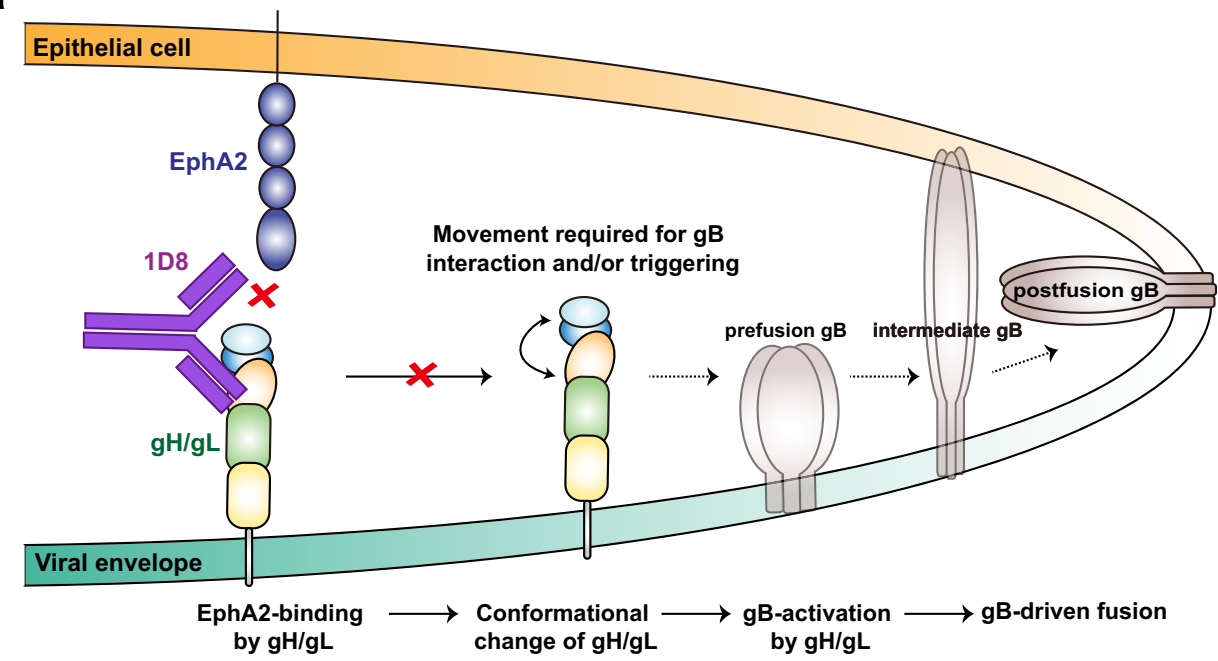

b

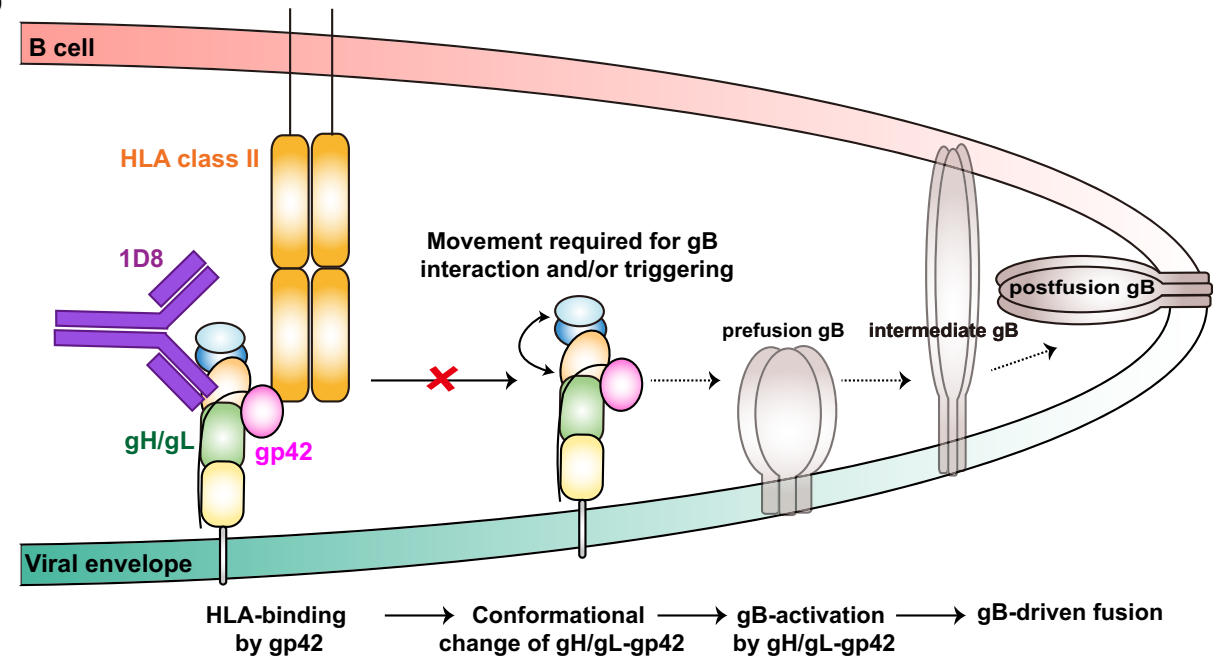

Fig. 6 Possible mechanisms of 1D8-mediated neutralization. a For epithelial cells, 1D8 could interfere the interaction between $g H / g L$ and EphA2 either by directly restricting access to the interface or by indirectly posing allosteric hindrance. It could also restrict the movement across the $\mathrm{D}-\mathrm{l} / \mathrm{D}$-II groove of $\mathrm{gH} / \mathrm{A}$ $\mathrm{gL}$ that is required for $\mathrm{gB}$ interaction and triggering. $\mathbf{b}$ For $\mathrm{B}$ cells, $1 \mathrm{D} 8$ could also restrict the movement across the $\mathrm{D}-\mathrm{l} / \mathrm{D}-\mathrm{Il} \mathrm{groove}$ of $\mathrm{gH} / \mathrm{gL}$ that is required for downstream viral entry. 1D8 does not appear influence interaction between gp42 and its receptor HLA class II.

on the vulnerable sites to elicit powerful neutralizing antibodies like 1D8, AMMO1, and 769B10.

\section{Methods}

Ethical standards. The utilization of human samples was approved by the Ethics Review Committee of the Sun Yat-sen University Cancer Center (SYSUCC, YP2009051) and conducted in accordance with the Declaration of Helsinki. Written informed consents forms were signed by all human research participants. All animal experiments with infectious EBV were performed in the animal biosafety level 2 facilities at Sun Yat-sen University Zhongshan School of Medicine, which was approved by the Committee on the Ethics of Animal Experiments of Sun Yat-sen University (SYSUCC, L102012019070D). The animal studies were carried out in strict accordance with the recommendations promulgated in the Guide for the Care and Use of Laboratory Animals of the Ministry of Science and Technology of the People's Republic of China.

Human subjects. We collected plasma samples from 48 participants including 23 histologically diagnosed NPC cases and 25 non-NPC high-risk healthy controls in a screening program in Sihui County in Guangdong Province of China from 2007 and 2018. Peripheral blood mononuclear cell (PBMC) sample of donors 27 were collected in 2018. The screening program has been introduced in detail in other manuscript ${ }^{60}$. Primary B cells were isolated from healthy donor PBMC using the CD19 MicroBead Kit (Miltenyi Biotec Cat\#130-117-034).
Cell lines. All cell lines were cultured at $37^{\circ} \mathrm{C}$ in a humidified atmosphere comprising $5 \% \mathrm{CO}_{2}$. $293 \mathrm{~T}$ cells (ATCC) were grown in DMEM (GIBCO Cat\#C11995500BT) + 10\% FBS (GIBCO Cat\#10099141). CHO K-1 cells (ATCC) were maintained in Ham's F-12 (GIBCO Cat\#11765054) +10\% FBS. Raji cells (ATCC), HNE1 cells ${ }^{61}$ and HK1 cells ${ }^{62}$ were maintained in RMPI1640 $+10 \%$ FBS Akata $\mathrm{B}$ cells ${ }^{63}$ harboring a modified EBV, in which the thymidine kinase gene has been replaced with a neomycin and green fluorescence protein (GFP) cassette (Akata-GFP), were grown in RMPI 1640 (GIBCO Cat\#C11875500BT) + 5\% FBS. 293F cells (ThermoFisher) were maintained in Freestyle 293 medium (Union Cat\#UP1000) with gentle shaking. Bmil-immortalized nasopharyngeal epithelial cells (NPEC1-Bmil) were cultured in keratinocyte serum-free medium (17005-075; Invitrogen, California). All cells were grown with $100 \mathrm{U} / \mathrm{ml}$ pencillin and $100 \mu \mathrm{g} / \mathrm{ml}$ streptomycin.

Humanized mice. The construction of the humanized mice was based on

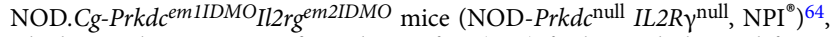
which were kept in a specific pathogen free (SPF) facility and obtained from BEIJING IDMO Co., Ltd. Animals were maintained under standard conditions of humidity $(50 \%)$, temperature $\left(25 \pm 2{ }^{\circ} \mathrm{C}\right)$ in a $12 \mathrm{~h}$ light and $12 \mathrm{~h}$ dark cycle. To generate the humanized immune system, mice were i.p. injected with a single dose of Busulfan at $20 \mathrm{mg} / \mathrm{kg}$ body weight. After $48 \mathrm{~h}$ post-injection, the mice received an intravenous tail injection of human CD34 + cells, which were isolated from umbilical cord blood (Beijing Novay biotech) with a purity of over $90 \%$. Human CD45+ cells in peripheral blood of each humanized mouse were detected at 4 and 8 weeks post engraftment by flow cytometry. 
Plasmids. The $\mathrm{gH} / \mathrm{gL}$ [residues 19 to $679 \mathrm{of} \mathrm{gH}$ and residues 24 to 137 of gL were linked by $(\mathrm{G} 4 \mathrm{~S})_{3}$ ] and gp42 (residue 34 to 223) fragments were amplified from the bacterial artificial chromosome (BAC) of EBV-M81 by PCR and cloned into the pcDNA3.1 plasmid with an N-terminal CD5 leader peptide and a C-terminal HIS Tag. Targeted mutations were introduced into pcDNA3.1-CD5-gH/gL using the ClonExpress MultiS One Step Cloning Kit (Vazyme Cat\# C113-02) and were confirmed by Sanger sequencing. The pCAGGS expression plasmids for $\mathrm{gH}, \mathrm{gL}, \mathrm{gB}$, and pT7EMCLuc (which carries a luciferase-containing reporter plasmid under the control of the T7 promoter) were kindly provided by Dr. R. Longnecker. EphA2 (27-534) fused with a C-terminal human IgG1-Fc domain by a (GGGGS) 3 linker was cloned into a pcDNA3.1 vector.

Recombinant antibody cloning. The $\mathrm{VH}$ and $\mathrm{VK} / \mathrm{V} \lambda$ genes of reference antibodies CL40, E1D1 and AMMO1 were obtained from PDB and codon optimized genes were synthesized by Tsingke Biological Technology Company. Antibody heavy chain and light chain variable gene fragments were obtained using separate primer pair ${ }^{65}$ with restriction enzyme cutting sites, including VH primers with 5'AgeI and 3'SalI, VK primers with 5'AgeI and 3'BsiWI, and V $\lambda$ primers with 5'AgeI and 3'Xhol. Then PCR products were cloned into antibody expression vectors containing the constant regions of human IgG1. The sequences of the recombinant plasmids were verified by Sanger sequencing.

Recombinant protein expression. The 293F cells were transfected with plasmids encoding EBV glycoproteins, EphA2-Fc and recombinant antibodies at a density of $1.5 \times 10^{6} \mathrm{cells} / \mathrm{ml}$ in Freestyle 293 medium using PEI (Polysciences Cat $\# 24765-1$ ) transfection reagent according to the manufacturer's instructions. After five days, the culture supernatant containing EBV glycoprotein was collected and passed through Ni-NTA resin (GE Healthcare Cat\#17-3712-02), followed by washing (PBS with $20 \mathrm{mM}$ imidazole, $\mathrm{pH} 7.4$ ) and elution (PBS with $250 \mathrm{mM}$ imidazole, $\mathrm{pH}$ 7.4). The proteins were further purified by size exclusion chromatography (SEC) and dialyzed into PBS. Clarified cell supernatant containing recombinant antibodies or EphA2-Fc was passed over Protein A agarose (GenScript Cat\#L00210), followed by extensive washing with PBS, and then eluted with $10 \mathrm{~mL}$ of $0.3 \mathrm{M}$ glycine, $\mathrm{pH} 2.0$ into $1 \mathrm{~mL}$ of $1 \mathrm{M}$ Tris $\mathrm{HCl}, \mathrm{pH}$ 8.0. Purified proteins were then dialyzed into PBS.

Recombinant protein biotinylation. $\mathrm{gH} / \mathrm{gL}$ were biotinylated at a theoretical 1.5:1 biotin/protein ratio using the EZ-Link Sulfo-NHS-Biotin (ThermoFisher Cat\#21338) at room temperature for $30 \mathrm{~min}$. Free biotin was removed by 3 successive rounds of dilution with PBS.

Preparation of the antigen-binding fragment. 1D8 Fab was obtained by digesting 1D8 IgG with Endoproteinase Lys-C (Sigma Cat\#11420429001) at $37^{\circ} \mathrm{C}(1 \mathrm{mg}$ IgG: $250 \mathrm{ng}$ Lys C) for $12 \mathrm{~h}$. Fab fragments were isolated with $\mathrm{Fc}$ fragments using protein A agarose, then further purified by SEC.

Bio-layer interferometry. Antibody competition binding assays (Octet Red 96, ForteBio, Pall LLC): $250 \mathrm{nM} \mathrm{gH/gL}$ was captured onto HIS1K sensors (ForteBio, Pall LLC) for $120 \mathrm{~s}$. The baseline interference was then read for $60 \mathrm{~s}$ in KB buffer (PBS, $0.1 \%$ BSA, $0.02 \%$ Tween). Then the sensor was loaded with 1D8 $(10 \mu \mathrm{g} / \mathrm{ml})$ or KB (blank) for $60 \mathrm{~s}$ and balanced in $\mathrm{KB}$ for $60 \mathrm{~s}$, followed by association with $10 \mu \mathrm{g} / \mathrm{ml}$ competitive antibodies (1D8, AMMO1, CL40, E1D1) for $120 \mathrm{~s}$ and association with $\mathrm{KB}$ for $120 \mathrm{~s}$. One gH/gL-1D8 loaded sensor was immersed in buffer as a reference during the association and dissociation steps and used to subtract the background signal. Antibody/EphA2 competition binding assays: $2 \mu \mathrm{g} / \mathrm{ml} \mathrm{gH/gL-biotin} \mathrm{was}$ immobilized on streptavidin biosensors (ForteBio, Pall LLC, Cat\# 18-5019), and then immersed into KB for $60 \mathrm{~s}$. Then the sensor was loaded with 1D8 (50 nM), AMMO1 $(50 \mathrm{nM}), 2 \mathrm{G} 4(50 \mathrm{nM})$ or KB (blank) for $60 \mathrm{~s}$ and balanced in KB for $60 \mathrm{~s}$, followed by associated with $1000 \mathrm{nM}$ EphA2-Fc for $100 \mathrm{~s}$ and association with KB for $120 \mathrm{~s}$. One $\mathrm{gH} / \mathrm{gL}$-antibody loaded sensor was immersed in buffer as a reference during the association and dissociation steps and used to subtract the background signal.

Surface plasmon resonance. The binding kinetics and affinity of antibodies for $\mathrm{gH} / \mathrm{gL}$ or their mutants were analyzed by SPR (Biacore $8 \mathrm{~K}$, GE Healthcare). Antihuman IgG $(\mathrm{Fc})$ antibody was covalently immobilized onto a CM5 sensor chip (GE Healthcare Cat\# BR-1005-30) via amine groups in $10 \mathrm{mM}$ sodium acetate buffer (pH 5.0) for a final RU of around 5000. Specifically, antibodies 1D8 or AMMO1 $(2 \mu \mathrm{g} / \mathrm{ml})$ were captured by anti-human IgG antibody for $10 \mathrm{~s}$. Diluted $\mathrm{gH} / \mathrm{gL}$ or their mutants were run at a flow rate of $30 \mu \mathrm{l} / \mathrm{min}$ in HBS-EP (aqueous buffer containing $0.01 \mathrm{M}$ HEPES pH 7.4, $0.15 \mathrm{M} \mathrm{NaCl}, 3 \mathrm{mM}$ EDTA and $0.05 \%(\mathrm{v} / \mathrm{v})$ Tween 20, filtered through a $0.2 \mu \mathrm{m}$ filter). The sensograms were fit to a 1:1 binding model using the Biacore Insight Evaluation Software (GE Healthcare).

Enzyme-linked immunosorbent assay (ELISA). For ELISA, $100 \mathrm{ng} /$ well of EBV glycoprotein was coated in 96-well enzyme-linked immunosorbent assay plates overnight at $4{ }^{\circ} \mathrm{C}$. Then, the plates were blocked with $5 \%$ bovine serum albumin (BSA) in PBS and $0.1 \%$ Tween-20 (blocking buffer) at $37^{\circ} \mathrm{C}$ for $1 \mathrm{~h}$. After blocking, the plates were washed three times with $0.1 \%$ Tween-20 in PBS (washing buffer).
Plasma samples or recombinant antibodies were diluted serially in blocking buffer and incubated at $37^{\circ} \mathrm{C}$ for $1 \mathrm{~h}$. Following three times of washing, a 1:4000 goat anti-human IgG-HRP (Promega Cat\#W4031) in blocking buffer was added to each well and incubated at $37^{\circ} \mathrm{C}$ for $45 \mathrm{~min}$. Plates were washed five times and incubated with $3,3^{\prime}, 5,5^{\prime}$-tetramethylbenzidine substrate (TMB) (TIANGEN Cat\#PA107-01) for $5 \mathrm{~min}$ at room temperature. Then $1 \mathrm{M}$ hydrochloric acid $(\mathrm{HCl})$ was added and the $\mathrm{OD}_{450}$ was read on a microplate reader (Epoch2).

For the binding analysis of $\mathrm{gH} / \mathrm{gL}$ mutants ( $<4$ angstrom cutoff), $500 \mathrm{ng} /$ well of antibody was coated in plates overnight at $4{ }^{\circ} \mathrm{C}$. The plates were then blocked and washed. The $\mathrm{gH} / \mathrm{gL}$ mutants were diluted serially in blocking buffer and incubated at $37^{\circ} \mathrm{C}$ for $1 \mathrm{~h}$. Following three times of washing, 1:3000 diluted mouse anti-his antibody (TRANSGEN BIOTECH Cat\#HT501-02) in blocking buffer was added to each well and incubated at $37^{\circ} \mathrm{C}$ for $1 \mathrm{~h}$. After three times of washing, a 1:5000 diluted goat anti-mouse-HRP antibody (Invitrogen Cat\#31430) was added and incubated at $37^{\circ} \mathrm{C}$ for $1 \mathrm{~h}$. The final steps were the same as above. For antibody binding to various $\mathrm{gH} / \mathrm{gL}$ mutants (4-6 angstrom cutoff), $293 \mathrm{~T}$ cells in 24-well plate were transfected with $500 \mathrm{ng} \mathrm{gH} / \mathrm{gL}$ mutated plasmids and $\mathrm{gH} / \mathrm{gL}$ protein secreted into the cell supernatants were captured by antibody-coated plates. Antibody binding and detection were conducted as routine ELISA assay.

B cells sorting. Cryopreserved $10^{7} \mathrm{PBMC}$ were thawed into $1 \mathrm{ml}$ preheated RPMI1640, centrifuged at $300 \times g$ for $5 \mathrm{~min}$, resuspended in $500 \mu \mathrm{l} \mathrm{FACS}$ buffer (PBS $+2 \% \mathrm{FBS})$, and incubated with $200 \mathrm{nM}$ his-tagged antigen $(\mathrm{gH} / \mathrm{gL})$ for $45 \mathrm{~min}$ at $4{ }^{\circ} \mathrm{C}$. The PBMC were then washed two times with $1 \mathrm{ml}$ FACS buffer and resuspended in $100 \mu \mathrm{l}$ FACS buffer. The PBMC were stained with the following antibodies: CD3-PE-Cy5 (BD Biosciences Cat\#555341) at a 1:25 dilution, CD14PE-Cy5 (eBioscience Cat\#15-0149-42) at a 1:50 dilution, CD16-PE-Cy5 (BD Biosciences Cat\#555408) at a 1:25 dilution, CD235a-PE-Cy5 (BD Biosciences Cat\#559944) at a 1:100 dilution, CD19-APC-Cy7 (BD Biosciences Cat\#348794) at a 1:100 dilution, CD20-PE-Cy7 (BD Biosciences Cat\#335793) at a 1:200 dilution, IgG-FITC (BD Biosciences Cat\#555786) at a 1:25 dilution, and anti-his-PE (BioLegend Cat\#362603) at a 1:20 dilution for $30 \mathrm{~min}$ at $4{ }^{\circ} \mathrm{C}$. The PBMC were washed three times with $1 \mathrm{ml} \mathrm{FACS}$ buffer and resuspended in $500 \mu \mathrm{l}$ FACS buffer, then subjected to FACS on a BD FACS Aria II (BD Biosciences).

Antigen-positive B cells (CD3-, CD14-, CD16-, CD235a-, CD19+, CD20+, IgG+, $\mathrm{PE}+$ ) were sorted individually into 96-well PCR vital-plates containing $20 \mu \mathrm{l}$ first strand buffer ( $5 \mu \mathrm{l}$ first strand buffer, $0.5 \mu \mathrm{l}$ of RNase inhibitor (Invitrogen Cat\#10777019), $1.25 \mu \mathrm{l}$ of $100 \mu \mathrm{M}$ DTT, $0.06 \mu \mathrm{l}$ of IGEPAL (Sigma Cat\#I8896).

VH/VL recovery from sorted cells. Wells containing sorted cells were mixed with $6 \mu \mathrm{l}$ of reverse transcription (RT) buffer containing $1.5 \mu \mathrm{l}$ mixed primers specific for human IgG, IgM, IgD, IgA1, IgA2, $\mathrm{K}$ and $\lambda$ constant gene regions, $1.5 \mu \mathrm{l}$ of $25 \mathrm{mM}$ dNTP mix (Invitrogen Cat\#10297117), and $0.25 \mu \mathrm{l}$ of superscript III reverse transcriptase (Invitrogen Cat\#18080085). The RT temperature program included $42^{\circ} \mathrm{C}$ for $10 \mathrm{~min}, 25^{\circ} \mathrm{C}$ for $10 \mathrm{~min}, 60^{\circ} \mathrm{C}$ for $50 \mathrm{~min}$, and $94^{\circ} \mathrm{C}$ for $5 \mathrm{~min}$, followed by a hold at $4^{\circ} \mathrm{C}$. The $\mathrm{VH}, \mathrm{VK}$ and $\mathrm{V} \lambda$ genes were amplified from $5 \mu \mathrm{l}$ of cDNA separately using nested PCR (HotStarTaq DNA Polymerase, QIAGEN Cat\#203205). The PCR products were purified and subjected to Sanger sequencing. Then, the $\mathrm{VH}, \mathrm{VK}$ and $\mathrm{V} \lambda$ variable genes were assembled into functional linear Ig gene expression cassettes by overlap-extension PCR. The function of the expressed antibodies was determined using ELISA screening.

Virus production. Akata cells carrying EBV, in which the thymidine kinase gene was interrupted with a double cassette expressing GFP and a neomycin resistance gene, were resuspended in FBS-free RPMI 1640 medium at a concentration of $2-3 \times 10^{6}$ cells per $\mathrm{ml}$, followed by induction with $0.75 \%(\mathrm{v} / \mathrm{v})$ of goat anti-human immunoglobulin G serum (Shuangliu Zhenglong Biochem Lab Cat\#H0111-6) for $6 \mathrm{~h}$ at $37^{\circ} \mathrm{C}$. After culture in fresh RPMI 1640 medium supplemented with 5\% FBS for 3 days, virus from the supernatant was collected under sterile conditions, passed through two Millipore filters $(0.8$ and $0.45 \mu \mathrm{m})$, concentrated 100 -fold by highspeed centrifugation at 50,000 g, and then resuspended in fresh FBS-free RPMI1640. The virus was stored at $80^{\circ} \mathrm{C}$ and thawed immediately before infection To assess the virus titer, 10 -fold dilutions of EBV were used to inoculate $2 \times 10^{5}$ PBMC per well in 24-well plates with $2 \mu \mathrm{g} / \mathrm{ml}$ cyclosporin A (CsA) (Sigma Cat\#C3662). The cultures were fed weekly by replacing half of the medium with fresh medium containing CsA. After 6 weeks, the $\mathrm{TD}_{50}$ was determined based on the number of proliferating lymphocytes in the wells ${ }^{54}$.

Neutralization assay. Plasma samples from study individuals or recombinant antibodies were incubated with nearly $1,000 \mathrm{TD}_{50}$ GFP-expressing EBV at serial dilutions for $3 \mathrm{~h}$ at $4{ }^{\circ} \mathrm{C}$. Then the mixtures were added to Raji B cells, HNE1 epithelial cells, primary B cells and NPEC1-Bmil and incubated for $3 \mathrm{~h}$ at $37^{\circ} \mathrm{C}$. Then the unbound virus was removed by washing with PBS twice. Infected cells were cultured in fresh medium for $48 \mathrm{~h}$, followed by detection and analysis of GFPpositive cells using a flow cytometer and FlowJo 10 software (FlowJo, USA). The neutralization rate of each sample was defined as: $\% \mathrm{GFP}+$ cells in the positive control well containing virus alone-\%GFP+ cells in the plasma or antibody containing well)/\%GFP + cells in the positive control well $\times 100$. 
EBV infection in humanized mice. At 8 weeks post CD34+ stem cells transfer, $400 \mu \mathrm{g}$ of experimental or control antibodies were i.p. injected per humanized mouse. After $24 \mathrm{~h}$, the mice received a dose of Akata EBV equivalent to $1000 \mathrm{TD}_{50}$ via i.v. injection. In the following period, the mice received a dose of $0.4 \mathrm{mg}$ antibody weekly. The blood collection and recording of body weight and health status were also done every week. The mice were euthanized 6 weeks post-EBV infection or earlier if they became clinically ill (e.g. body weight loss of approximately 20\%). For the second animal experiment, humanized mice received a single dose of $400 \mu \mathrm{g}$ antibody before EBV challenge. All animals were monitored for body weight, survival, as well as virological parameters up to 7 weeks.

Detection of EBV DNA in blood and tissues. DNA was extracted from the peripheral blood $(100 \mu \mathrm{l})$ or tissues of the mice using commercial DNA extraction kits (Omega Cat\#D3392-02). The EBV genome copy numbers were determined by real-time PCR (Roche Light Cycler 480) using the TaqMan BamHI probes (sense: 5'-CCCAACACTCCACCACACC-3'; antisense: 5'-TCTTAGGAGCTGTCCGAG GG-3'). The copy numbers of EBV were quantified using a standard EBV genome (BDS biotech Cat\#BDS-BW-087) as control.

H\&E staining, IHC, and in situ hybridization. Tissues were fixed in 10\% formalin and embedded in paraffin. Consecutive sections were used for staining with H\&E. Immunostaining of human $\mathrm{T}$ cells and B cells was performed using hCD3 antibody (VENTANA Cat\#790-4341) and hCD20 antibody (VENTANA Cat\#760-2531) at 1:200 dilution. EBERs were stained by in situ hybridization using the EBER detection kit (ZSGB-BIO Cat\#ISH-7001-100), according to the manufacturer's instructions. Histological staining was evaluated by experienced pathologists.

Detection of human immune cells in the blood of humanized mice. Peripheral blood of mice was treated with $1 \mathrm{ml}$ red blood cell lysis buffer (BioLegend Cat\#420301) at room temperature for $10 \mathrm{~min}$. Then the cells were centrifuged at $300 \mathrm{~g}$, washed twice with PBS, resuspended in PBS, and stained with antibodies including anti-human CD45-PE (BD Biosciences Cat\#555483), CD3-PerCP-Cy5.5 (BD Biosciences Cat\#560835) and CD20-FITC (BD Biosciences Cat\#555622) at 1:100 dilution for $30 \mathrm{~min}$ at $4{ }^{\circ} \mathrm{C}$. After washing with PBS, the percentage of CD3+ or $\mathrm{CD} 20+$ cells among the $\mathrm{CD} 45+$ cells was quantified using a flow cytometer.

Cell-surface binding assays. For the cell-surface binding assay, $1 \mathrm{mg}$ of $\mathrm{gH} / \mathrm{gL}$ biotin conjugated with SA-PE (gH/gL-PE) was diluted in $10 \mathrm{ml}$ of PBS into individual wells of a 96 well plate. An equimolar amount of gp42 was added to select wells containing gH/gL-PE. $5 \mathrm{mg} / \mathrm{ml}$ of monoclonal antibodies, including 1D8, AMMO1, or $2 \mathrm{G} 4$, were added to select wells containing $\mathrm{gH} / \mathrm{gL}$ with or without gp42 and incubated for $1 \mathrm{~h}$ at $37^{\circ} \mathrm{C}$. At the same time, adherent $\mathrm{HK} 1$ cells were trypsinized (NCM Biotech Cat\#C40100), washed with RMPI 1640 and then allowed to recover at $37^{\circ} \mathrm{C}$ in a humidified atmosphere comprising $5 \% \mathrm{CO}_{2}$ for $1 \mathrm{~h}$ with gentle agitation twice during the period. Recovered HK1 and Raji cells were pelleted by centrifugation at $300 \mathrm{~g}$ for $5 \mathrm{~min}$ and then resuspended at a density of $2 \times 10^{6} \mathrm{cells} / \mathrm{ml}$ in ice cold $0.5 \%$ bovine serum albumin (BSA) in PBS. Then, $100 \mu \mathrm{l}$ of the HK1 or Raji cells suspension were added to wells containing SA-PE, gH/gLPE with or without gp42 and antibodies, and incubated on ice for $1 \mathrm{~h}$. The cells were pelleted by centrifugation at $300 \mathrm{~g}$ for $5 \mathrm{~min}$, washed with $1 \mathrm{ml}$ of ice cold $0.5 \%$ BSA in PBS, pelleted again and resuspended in $10 \%$ phosphate buffered formalin. The amount of PE staining was quantified using a flow cytometer.

Virus-free fusion assay. Effector $\mathrm{CHO}-\mathrm{K} 1$ cells were transiently transfected with expression plasmid (pCAGGS-gH, pCAGGS-gL, pCAGGS-gB and pT7EMCLuc, which carries a luciferase-containing reporter plasmid under the control of the T7 promoter). Target cells (HEK-293T) were transfected with expression plasmid pCAGT7 (expressing T7 DNA polymerase). After $24 \mathrm{~h}$, the effector cells were trypsinized and resuspended at a density of $1 \times 10^{6}$ cells $/ \mathrm{ml}$. Aliquots comprising $250 \mu \mathrm{l} /$ well of effector cell suspension was pre-incubated with $2 \mu \mathrm{g} 1 \mathrm{D} 8$, AMMO1 or $2 \mathrm{G} 4$ antibody at $37^{\circ} \mathrm{C}$ for $1 \mathrm{~h}$. Then the target cells were also trypsinized and resuspended at a density of $1 \times 10^{6} \mathrm{cells} / \mathrm{ml}$. An aliquot comprising $250 \mu \mathrm{l}$ of the effector cell suspension was added to the effector cells with or without antibody. After $24 \mathrm{~h}$, the medium was aspirated and the cells were lysed in $100 \mu \mathrm{l}$ of luciferase agent (Dual-Glo Luciferase Assay System Cat\#E2940). Then, $75 \mu$ of cell lysate was transferred to a white-bottom assay plate and luciferase activity was read on a GloMax-96 Microplate Luminometer (Promega).

Cell-surface staining. Following $24 \mathrm{~h}$ after expression plasmid transfection, the effector CHO-K1 cells were trypsinized and resuspended at a density of $1 \times 10^{6} \mathrm{cells} / \mathrm{ml}$. The expression level of $\mathrm{gH} / \mathrm{gL}$ was detected using the indicated antibody. AMMO1 and $1 \mathrm{D} 8$ were used for $\mathrm{gH} / \mathrm{gL}$ staining and 2G4 as a control. Then, $10 \mu \mathrm{g} / \mathrm{ml}$ of antibody was added to the cell suspension and incubated at $4{ }^{\circ} \mathrm{C}$ for $1 \mathrm{~h}$. The cells were washed twice with PBS and stained with human IgG-PerCP-Cy5.5 (PC5.5) (BioLegend Cat\# 409312) at a 1:100 dilution. After washing with PBS, the percentage of PC5.5+ cells was quantified using a flow cytometer (CytoFLEX, BECKMAN).
Crystallization of the 1D8 Fab and data collection. To purify the gH/gL-1D8 Fab complex, 1D8 Fab was incubated with $\mathrm{gH} / \mathrm{gL}$ for $1 \mathrm{~h}$ on ice in HBS buffer, and the mixture was then subjected to gel filtration chromatography. Fractions containing the complex were pooled and concentrated to $10 \mathrm{mg} / \mathrm{ml}$. Crystals were successfully grown at $18{ }^{\circ} \mathrm{C}$ in sitting drops, over wells containing $200 \mathrm{mM}$ sodium citrate, $100 \mathrm{mM}$ HEPES sodium salt, $\mathrm{pH} 7.5,15 \% \mathrm{w} / \mathrm{v}$ MPD. The drops were made by mixing $200 \mathrm{nl}$ gH/gL-1D8 Fab complex in HBS buffer with $200 \mathrm{nl}$ well solution. Crystals were harvested, soaked briefly in $200 \mathrm{mM}$ sodium citrate, $100 \mathrm{mM}$ HEPES sodium salt, $\mathrm{pH} 7.5,15 \% \mathrm{w} / \mathrm{v}$ MPD, $20 \%$ glycerol, and flash-frozen in liquid nitrogen. Diffraction data were collected at the BL17U beam line of the Shanghai Synchrotron Research Facility (SSRF). Diffraction data were processed with HKL2000 and the crystal diffracted to $4.2 \AA$. The data processing statistics are listed in Supplementary Table 3.

Structure solution and refinement. The structure was determined via the molecular replacement method using PHASER in CCP4 suite. The search models were $\mathrm{gH} / \mathrm{gL}$ (PDB code 5T1D) and the antibody with the highest sequence identity with 1D8. Density map improvement by atoms update and refinement was performed with ARP/wARP29. Subsequent model building and refinement were performed using COOT and PHENIX, respectively. Final Ramachandran statistics indicated that $91.48 \%$ residues were in favored conformations, $7.06 \%$ allowed and $1.46 \%$ outliers for the final structure. The structural refinement statistics are listed in Supplementary Table 3. All structural figures were generated with PyMol (DeLano, 2002).

Cryo-EM sample preparation and data collection. We reconstituted the complex of the $\mathrm{gH} / \mathrm{gL}$ bound to the 1D8 Fab and the AMMO1 Fab at 1:1:1 molar ratio. Aliquots of complexes $(4 \mu \mathrm{l}, 0.5 \mathrm{mg} / \mathrm{ml}$, in buffer containing $20 \mathrm{mM}$ Tris $\mathrm{pH} 8.0$ and $150 \mathrm{mM} \mathrm{NaCl}$ ) were applied to glow-discharged holey carbon grids (Quantifoil grid, $\mathrm{Au} 300$ mesh, R1.2/1.3). The grids were then blotted and plunge-frozen into liquid ethane using Vitrobot Mark IV (Thermo Fisher Scientific). Images for complexes were recorded using $300 \mathrm{kV}$ FEI Titan Krios microscope (Thermo Fisher Scientific) at Tsinghua University. We collect $~ 5000$ movies for complexes at a nominal magnification of $29,000 \times$ and at a defocus range between -1.2 and -1.5 $\mu \mathrm{m}$. Each movie has a total accumulate exposure of $50 \mathrm{e}-/ \AA^{2}$ fractionated in 32 frames of $175 \mathrm{~ms}$ exposure. The final image was binned 2-fold to a pixel size of $0.97 \AA$ A. Motion Correction (MotionCor2 v.1.2.6) ${ }^{66}$, CTFestimation (GCTF v.1.18) ${ }^{67}$ and non-templated particle picking (Gautomatch v.0.56, http://www.mrclmb.cam.ac.uk/kzhang/) were automatically executed by TsingTitan.py program. Sequential data processing and 2D projection of gH/gL-1D8-AMMO1 model was carried out on RELION3.168

Statistical analysis. Unless noted otherwise, a two-tailed, unpaired $t$-test was used to assess statistical significance. Statistical calculations were performed in GraphPad Prism 8. The number of replicates and a description of the statistical method are provided in the corresponding figure legends. Differences with $P$ values of less than 0.05 were considered to be statistically significant. ${ }^{*} p<0.05,{ }^{* *} p<0.01$, $* * * p<0.001$, ns $=$ not significant.

Reporting summary. Further information on research design is available in the Nature Research Reporting Summary linked to this article.

\section{Data availability}

Data generated or analyzed during this study are included in this published article (and its supplementary information files). All other data are also available from the corresponding author upon reasonable requests. The atomic model of 1D8-gH/gL (PDB ID: 7D5Z; https://www.rcsb.org/structure/7D5Z) has been deposited in the Protein Data Bank. The Sequences of 1D8 antibodies have been deposited in Genbank with accession codes OK484490(1D8-HC) and OK484491(1D8-KC). Source data are provided with this paper.

Received: 20 January 2021; Accepted: 26 October 2021; Published online: 16 November 2021

\section{References}

1. de-Thé G., et al. Sero-epidemiology of the Epstein-Barr virus: preliminary analysis of an international study-a review. IARC Sci Publ, 3-16 (1975).

2. Young, L. S., Yap, L. F. \& Murray, P. G. Epstein-Barr virus: more than 50 years old and still providing surprises. Nat. Rev. Cancer 16, 789-802 (2016).

3. Cohen, J. I., Fauci, A. S., Varmus, H. \& Nabel, G. J. Epstein-Barr virus: an important vaccine target for cancer prevention. Sci. Transl. Med. 3, $107 \mathrm{fs} 107$ (2011).

4. Young, L. S. \& Dawson, C. W. Epstein-Barr virus and nasopharyngeal carcinoma. Chin. J. Cancer 33, 581-590 (2014). 
5. Tan, R. et al. Clinical utility of Epstein-Barr virus DNA and other liquid biopsy markers in nasopharyngeal carcinoma. Cancer Commun. (Lond.) 40, 564-585 (2020).

6. Henrickson, S. E. To EBV or not to EBV: Rational vaccine design for a common infection. Sci Immunol 3, eaat9661 (2018).

7. van Zyl, D. G., Mautner, J. \& Delecluse, H. J. Progress in EBV vaccines. Front Oncol. 9, 104 (2019).

8. Cohen, J. I. Epstein-barr virus vaccines. Clin. Transl. Immunol. 4, e32 (2015).

9. Cohen, J. I., Mocarski, E. S., Raab-Traub, N., Corey, L. \& Nabel, G. J. The need and challenges for development of an Epstein-Barr virus vaccine. Vaccine 31, B194-B196 (2013).

10. Young, L. S. A novel Epstein-Barr virus subtype associated with nasopharyngeal carcinoma found in South China. Cancer Commun. (Lond.) 40, 60-62 (2020).

11. $\mathrm{Bu}, \mathrm{W}$. et al. Immunization with components of the viral fusion apparatus elicits antibodies that neutralize Epstein-Barr virus in B cells and epithelial cells. Immunity 50, 1305-1316 e1306 (2019).

12. Coghill, A. E. et al. High levels of antibody that neutralize B-cell infection of Epstein-Barr virus and that bind EBV gp350 are associated with a lower risk of nasopharyngeal carcinoma. Clin. Cancer Res 22, 3451-3457 (2016).

13. Coghill, A. E. et al. Evaluation of total and IgA-specific antibody targeting Epstein-Barr virus glycoprotein 350 and nasopharyngeal carcinoma risk. $J$. Infect. Dis. 218, 886-891 (2018).

14. Bu, W. et al. Kinetics of Epstein-Barr virus (EBV) neutralizing and virusspecific antibodies after primary infection with EBV. Clin. Vaccin. Immunol. 23, 363-369 (2016).

15. Sashihara, J., Burbelo, P. D., Savoldo, B., Pierson, T. C. \& Cohen, J. I. Human antibody titers to Epstein-Barr Virus (EBV) gp350 correlate with neutralization of infectivity better than antibody titers to EBV gp42 using a rapid flow cytometry-based EBV neutralization assay. Virology 391, 249-256 (2009).

16. Sok, D. \& Burton, D. R. Recent progress in broadly neutralizing antibodies to HIV. Nat. Immunol. 19, 1179-1188 (2018).

17. Saphire, E. O., Schendel, S. L., Gunn, B. M., Milligan, J. C. \& Alter, G. Antibody-mediated protection against Ebola virus. Nat. Immunol. 19, 1169-1178 (2018).

18. Yu, F. et al. Receptor-binding domain-specific human neutralizing monoclonal antibodies against SARS-CoV and SARS-CoV-2. Signal Transduct. Target Ther. 5, 212 (2020).

19. Walker, L. M. \& Burton, D. R. Passive immunotherapy of viral infections: 'super-antibodies' enter the fray. Nat. Rev. Immunol. 18, 297-308 (2018).

20. Lanzavecchia, A., Fruhwirth, A., Perez, L. \& Corti, D. Antibody-guided vaccine design: identification of protective epitopes. Curr. Opin. Immunol. 41, 62-67 (2016)

21. Hutt-Fletcher, L. M. EBV glycoproteins: where are we now? Future Virol. 10, 1155-1162 (2015).

22. Mohl, B. S., Chen, J. \& Longnecker, R. Gammaherpesvirus entry and fusion: a tale how two human pathogenic viruses enter their host cells. Adv. Virus Res 104, 313-343 (2019).

23. Haque, T. et al. A mouse monoclonal antibody against Epstein-Barr virus envelope glycoprotein 350 prevents infection both in vitro and in vivo. $J$. Infect. Dis. 194, 584-587 (2006).

24. Snijder, J. et al. An antibody targeting the fusion machinery neutralizes dualtropic infection and defines a site of vulnerability on Epstein-Barr virus. Immunity 48, 799-811 e799 (2018).

25. Cui, X. et al. Rabbits immunized with Epstein-Barr virus $\mathrm{gH} / \mathrm{gL}$ or $\mathrm{gB}$ recombinant proteins elicit higher serum virus neutralizing activity than gp350. Vaccine 34, 4050-4055 (2016).

26. Zhu, Q.-Y. et al. Advances in pathogenesis and precision medicine for nasopharyngeal carcinoma. MedComm. 2, 175-206 (2021).

27. Connolly, S. A., Jackson, J. O., Jardetzky, T. S. \& Longnecker, R. Fusing structure and function: a structural view of the herpesvirus entry machinery. Nat. Rev. Microbiol. 9, 369-381 (2011).

28. Singh, S., et al. Neutralizing antibodies protect against oral transmission of lymphocryptovirus. Cell Rep. Med. 1, 100033(2020).

29. Mohl, B. S., Chen, J., Sathiyamoorthy, K., Jardetzky, T. S. \& Longnecker, R. Structural and Mechanistic Insights into the Tropism of Epstein-Barr Virus Mol. Cells 39, 286-291 (2016).

30. Connolly, S. A., Jardetzky, T. S. \& Longnecker, R. The structural basis of herpesvirus entry. Nat. Rev. Microbiol. 19, 110-121 (2020).

31. Chesnokova, L. S. \& Hutt-Fletcher, L. M. Epstein-Barr virus infection mechanisms. Chin. J. Cancer 33, 545-548 (2014).

32. Matsuura, H., Kirschner, A. N., Longnecker, R. \& Jardetzky, T. S. Crystal structure of the Epstein-Barr virus (EBV) glycoprotein H/glycoprotein L (gH/ gL) complex. Proc. Natl Acad. Sci. USA 107, 22641-22646 (2010).

33. Mohl, B. S., Sathiyamoorthy, K., Jardetzky, T. S. \& Longnecker, R. The conserved disulfide bond within domain II of Epstein-Barr virus gH has divergent roles in membrane fusion with epithelial cells and B cells. J. Virol. 88, 13570-13579 (2014)

34. Chen, J., Jardetzky, T. S. \& Longnecker, R. The large groove found in the $\mathrm{gH} /$ $\mathrm{gL}$ structure is an important functional domain for Epstein-Barr virus fusion. J. Virol. 87, 3620-3627 (2013).

35. Sathiyamoorthy, K. et al. Assembly and architecture of the EBV B cell entry triggering complex. PLoS Pathog. 10, e1004309 (2014).

36. Kanekiyo, M. et al. Rational design of an Epstein-Barr virus vaccine targeting the receptor-binding site. Cell 162, 1090-1100 (2015).

37. Young, K. A., Herbert, A. P., Barlow, P. N., Holers, V. M. \& Hannan, J. P. Molecular basis of the interaction between complement receptor type 2 (CR2/ CD21) and Epstein-Barr virus glycoprotein gp350. J. Virol. 82, 11217-11227 (2008).

38. Szakonyi, G. et al. Structure of the Epstein-Barr virus major envelope glycoprotein. Nat. Struct. Mol. Biol. 13, 996-1001 (2006).

39. Sathiyamoorthy, K. et al. Structural basis for Epstein-Barr virus host cell tropism mediated by gp42 and gHgL entry glycoproteins. Nat. Commun. 7, 13557 (2016).

40. Mullen, M. M., Haan, K. M., Longnecker, R. \& Jardetzky, T. S. Structure of the Epstein-Barr virus gp42 protein bound to the MHC class II receptor HLADR1. Mol. Cell 9, 375-385 (2002).

41. Kirschner, A. N., Omerovic, J., Popov, B., Longnecker, R. \& Jardetzky, T. S. Soluble Epstein-Barr virus glycoproteins $\mathrm{gH}, \mathrm{gL}$, and gp42 form a 1:1:1 stable complex that acts like soluble gp42 in B-cell fusion but not in epithelial cell fusion. J. Virol. 80, 9444-9454 (2006).

42. Xiong, D. et al. Nonmuscle myosin heavy chain IIA mediates Epstein-Barr virus infection of nasopharyngeal epithelial cells. Proc. Natl Acad. Sci. USA 112, 11036-11041 (2015)

43. Chen, J. et al. Ephrin receptor A2 is a functional entry receptor for EpsteinBarr virus. Nat. Microbiol. 3, 172-180 (2018).

44. Zhang, H. et al. Ephrin receptor A2 is an epithelial cell receptor for EpsteinBarr virus entry. Nat. Microbiol. 3, 1-8 (2018).

45. Wang, H. B. et al. Neuropilin 1 is an entry factor that promotes EBV infection of nasopharyngeal epithelial cells. Nat. Commun. 6, 6240 (2015).

46. Chen, J. \& Longnecker, R. Epithelial cell infection by Epstein-Barr virus. FEMS Microbiol. Rev. 43, 674-683 (2019).

47. Sathiyamoorthy, K. et al. Inhibition of EBV-mediated membrane fusion by anti-gHgL antibodies. Proc. Natl Acad. Sci. USA 114, E8703-E8710 (2017).

48. Liu, Z. et al. Two Epstein-Barr virus-related serologic antibody tests in nasopharyngeal carcinoma screening: results from the initial phase of a cluster randomized controlled trial in Southern China. Am. J. Epidemiol. 177, 242-250 (2013)

49. Liu, Y. et al. Establishment of VCA and EBNA1 IgA-based combination by enzyme-linked immunosorbent assay as preferred screening method for nasopharyngeal carcinoma: a two-stage design with a preliminary performance study and a mass screening in southern China. Int J. Cancer 131 406-416 (2012).

50. Fujiwara, S., Imadome, K. \& Takei, M. Modeling EBV infection and pathogenesis in new-generation humanized mice. Exp. Mol. Med. 47, e135 (2015).

51. Lee, E. K. et al. Effects of lymphocyte profile on development of EBV-induced lymphoma subtypes in humanized mice. Proc. Natl Acad. Sci. USA 112 , 13081-13086 (2015)

52. Munz, C. Humanized mouse models for Epstein Barr virus infection. Curr. Opin. Virol. 25, 113-118 (2017).

53. Audet, J. et al. Molecular characterization of the monoclonal antibodies composing ZMAb: a protective cocktail against Ebola virus. Sci. Rep. 4, 6881 (2014).

54. Yajima, M. et al. A new humanized mouse model of Epstein-Barr virus infection that reproduces persistent infection, lymphoproliferative disorder, and cell-mediated and humoral immune responses. J. Infect. Dis. 198, 673-682 (2008).

55. Caves, E. A. et al. Air-liquid interface method to study Epstein-Barr virus pathogenesis in nasopharyngeal epithelial cells. mSphere 3, e00152 (2018)

56. Lin, R. et al. Development of a robust, higher throughput green fluorescent protein (GFP)-based Epstein-Barr Virus (EBV) micro-neutralization assay. J. Virol. Methods 247, 15-21 (2017).

57. Odumade, O. A., Hogquist, K. A. \& Balfour, H. H. Jr. Progress and problems in understanding and managing primary Epstein-Barr virus infections. Clin. Microbiol Rev. 24, 193-209 (2011).

58. Omerovic, J., Lev, L. \& Longnecker, R. The amino terminus of Epstein-Barr virus glycoprotein $\mathrm{gH}$ is important for fusion with epithelial and B cells. J. Virol. 79, 12408-12415 (2005).

59. Mohl, B. S., Chen, J., Park, S. J., Jardetzky, T. S. \& Longnecker, R. Epstein-Barr virus fusion with epithelial cells triggered by $\mathrm{gB}$ is restricted by a $\mathrm{gL}$ glycosylation site. J. Virol. 91, e01255 (2017). 
60. Zhu, Q. Y. et al. Association between antibody responses to Epstein-Barr virus glycoproteins, neutralization of infectivity, and the risk of nasopharyngeal carcinoma. mSphere 5, e00901 (2020).

61. Zhan, F. et al. [Primary study of differentially expressed cDNA sequences in cell line HNE1 of human nasopharyngeal carcinoma by cDNA representational difference analysis]. Zhonghua Yi Xue Yi Chuan Xue Za Zhi 15, 341-344 (1998).

62. Huang, D. P. et al. Establishment of a cell line (NPC/HK1) from a differentiated squamous carcinoma of the nasopharynx. Int J. Cancer 26, 127-132 (1980).

63. Molesworth, S. J., Lake, C. M., Borza, C. M., Turk, S. M. \& Hutt-Fletcher, L. M. Epstein-Barr virus $\mathrm{gH}$ is essential for penetration of $\mathrm{B}$ cells but also plays a role in attachment of virus to epithelial cells. J. Virol. 74, 6324-6332 (2000).

64. Guo, S. et al. Oncological and genetic factors impacting PDX model construction with NSG mice in pancreatic cancer. FASEB J. 33, 873-884 (2019).

65. Liao, H. X. et al. High-throughput isolation of immunoglobulin genes from single human B cells and expression as monoclonal antibodies. J. Virol. Methods 158, 171-179 (2009).

66. Zheng, S. Q. et al. MotionCor2: anisotropic correction of beam-induced motion for improved cryo-electron microscopy. Nat. Methods 14, 331-332 (2017).

67. Zhang, K. Gctf: Real-time CTF determination and correction. J. Struct. Biol. 193, 1-12 (2016).

68. Zivanov, J., Nakane, T. \& Scheres, S. H. W. Estimation of high-order aberrations and anisotropic magnification from cryo-EM data sets in RELION-3.1. IUCrJ 7, 253-267 (2020).

\section{Acknowledgements}

The authors thank Chang Song and Cui Qiao from Beijing IDMO Company for help with the animal experiment. The plasmids pCAGGS-T7, pCAGGS-gH, pCAGGS-gL, pCAGGS-gB, and pT7EMCLuc were kindly provided by Professor Richard Longnecker. This work was supported by the following grant supports: the National Key Research and Development Program of China (2017YFA0505600, 2016YFA0502100,

2018ZX10731101-002, 2017ZX10201101, 2020YFC0848800, and 2020YFC0849900), the National Natural Science Foundation of China (81530065, 81520108022, 81830090, and $81621004)$, Guangdong Province key research and development program (2019B020226002) and Beijing Municipal Science \& Technology Commission (Z181100001918043, D171100000517, and Z201100005420019).

\section{Author contributions}

L.Z., M.Z., and X.W. conceived, designed, and supervised the entire study. Q.Z. and S.S. did antibody isolation and sequencing under the conduction of Y.Z. Q.Z., and S.S. did antibody binding analysis and virus neutralization. Q.Z., X.Z., and Y.P. performed the antibody protection experiment in humanized mice. J.Y., S.S., and Z.Y. collected crystal structure of gH/gL-1D8 Fab complex and did cryo-EM structure of gH/gL-1D8 FabAMMO1 Fab complex. S.S. and C.S. performed the SPR and BLI experiments. Q.Z. and L.Y.Z. did the binding analysis of gH/gL mutants. S.Y. evaluated the histological staining S.P., S.C., and X.S. provided materials and advice. Q.Z., S.S., J.Y., X.W., M.Z., and L.Z. had full access to the data in the study, generated figures and tables, and take responsibility for the integrity and accuracy of the data presentation. L.Z., Q.Z., S.S., and J.Y. wrote the original draft. M.Z. and X.W. reviewed and edited the manuscript. All authors approved the final version of the manuscript.

\section{Competing interests}

The authors declare the following competing interests: Patent applications have been filed on monoclonal antibodies that cover 1D8 presented here (patent application number: CN202010363336.X; patent applicants: Sun Yat-sen University Cancer Center and Tsinghua University). Q.Z., S.S., S.C., L.Z., and M.Z. are the inventors. All other authors declare no competing interests.

\section{Additional information}

Supplementary information The online version contains supplementary material available at https://doi.org/10.1038/s41467-021-26912-6.

Correspondence and requests for materials should be addressed to Xinquan Wang, Mu-Sheng Zeng or Linqi Zhang.

Peer review information Nature Communications thanks the anonymous reviewer(s) for their contribution to the peer review of this work.

Reprints and permission information is available at http://www.nature.com/reprints

Publisher's note Springer Nature remains neutral with regard to jurisdictional claims in published maps and institutional affiliations.

pen Access This article is licensed under a Creative Commons Attribution 4.0 International License, which permits use, sharing, adaptation, distribution and reproduction in any medium or format, as long as you give appropriate credit to the original author(s) and the source, provide a link to the Creative Commons license, and indicate if changes were made. The images or other third party material in this article are included in the article's Creative Commons license, unless indicated otherwise in a credit line to the material. If material is not included in the article's Creative Commons license and your intended use is not permitted by statutory regulation or exceeds the permitted use, you will need to obtain permission directly from the copyright holder. To view a copy of this license, visit http://creativecommons.org/ licenses/by/4.0/.

(C) The Author(s) 2021 